\title{
New Substructure Filters for Removal of Pan Assay Interference Compounds (PAINS) from Screening Libraries and for Their Exclusion in Bioassays
}

\author{
Jonathan B. Baell*,†, and Georgina A. Holloway ${ }^{\dagger, *}$ \\ ${ }^{\dagger}$ The Walter and Eliza Hall Institute of Medical Research, $1 G$ Royal Parade, Parkville, Victoria 3052, Australia and ${ }^{\star}$ Cancer Therapeutics-CRC \\ P/L, 4 Research Avenue, La Trobe R\&D Park, Bundoora, Victoria 3086, Australia
}

Received July 31, 2009

This report describes a number of substructural features which can help to identify compounds that appear as frequent hitters (promiscuous compounds) in many biochemical high throughput screens. The compounds identified by such substructural features are not recognized by filters commonly used to identify reactive compounds. Even though these substructural features were identified using only one assay detection technology, such compounds have been reported to be active from many different assays. In fact, these compounds are increasingly prevalent in the literature as potential starting points for further exploration, whereas they may not be.

\section{Introduction}

High throughput screening $\left(\mathrm{HTS}^{a}\right)$ is a key discipline undertaken by pharmaceutical companies as part of successful drug discovery. It is inevitable that hits from HTS campaigns comprise predominantly false positives among the real hits -if there are any. ${ }^{1}$ Compounds can be regarded as false positives for a number of reasons, for example, those that interfere in binding interactions by forming aggregates, ${ }^{2-5}$ those that are protein-reactive, ${ }^{6,7}$ or those that directly interfere in assay signaling. Aggregate formation and related behavior can be minimized by the inclusion of surfactant in the primary screening protocol, ${ }^{2,8}$ while the most reactive compounds can be largely weeded out before purchase by the use of well publicized functional group filters. ${ }^{9-11}$ However, it is clear that much about the nature of protein-reactive compounds remains to be known. With respect to the third cause of false positives, interference in assay signaling, it is not always clear which compounds might interfere with the primary screening assay technology until they are purchased and tested in an appropriately designed counter screen for assay interference.

The current chemical biology renaissance has seen HTS gain increasing traction in academic laboratories as a viable means to furnish tool compounds as well as starting points for therapeutic development. In 2003, our Institute established a screening library of 93212 compounds from commercial vendors. While now there are many dozens of such initiatives, at that time we were one of only a handful of academic laboratories worldwide to do so on this scale. The guiding philosophy behind our selection criteria was that being

*To whom correspondence should be addressed. Phone: +6139345 2108. Fax: +6139345 2211. E-mail: jbaell@wehi.edu.au.

${ }^{a}$ Abbreviations: AMH, Australian Medicines Handbook; CTX, CRC for Cancer Therapeutics; DABCO, 1,4-diazabicyclo[2.2.2]octane; FP, fluorescence polarization; HTRF, homogeneous time-resolved fluorescence; HTS, high throughput screening; MDDR, MDL Drug Data Report; MOA, mechanism of action; PAINS, pan assay interference compounds; SAR, structure-activity relationship; WEHI, Walter and Eliza Hall Institute of Medical Research. espoused by proponents of lead-like simplicity rather than drug-like complexity for furnishing more optimizable screening hits as better starting points for drug development that better cover diversity space. ${ }^{12,13}$ We have commented on this elsewhere. ${ }^{14,15}$ We also removed all compounds more than $85 \%$ similar to any other compound as determined by the Tanimoto coefficient, as we found this to be the most simple and yet still reasonable way of removing large numbers of similar analogues for highly populated chemistries while still retaining a skeleton structure-activity relationship (SAR) set. We selected from only four large vendors, as we determined that there was significant overlap between many of the 15 vendor databases under investigation, a finding that has since been confirmed. ${ }^{16}$ Vendor selection was also influenced by independently obtained referees reports. We largely adhered to published guidelines ${ }^{9-11}$ for removal of inappropriately reactive functional groups, as summarized in Table 1 (see Table S1 in Supporting Information (SI) for a more complete listing). However, some groups such as aminothiophenes, azo, anilines, oximes, hydrazones, thioethers, thiocarbonyls, ketones, esters, catechols, quinones, and some $\alpha, \beta$-unsaturated carbonyl groups we retained. Where inclusion of these groups in screening is advised against, ${ }^{9-11,16}$ it is generally on the basis of poor development potential or toxicity or, in the case of esters, hydrolytic liability on storage. Our reasoning for retaining these groups was that if such a compound furnished the only hit for a given target, unwanted features could be removed during medicinal chemistry optimization. Furthermore, we anticipated that thioether, hydrazone, and ester linkages, for example, might link potential binding elements that would otherwise not be represented. We would be concerned if such compounds also interfered in HTS assays, but at the stage of library implementation we had no reason to suspect this. We note importantly that analytical techniques have since confirmed compound integrity for more than $95 \%$ of furnished screening hits.

To date, we have run more than 40 primary screening campaigns against enzymes, ion channels, protein-protein 
Table 1. Functional Groups Commonly Recommended as Unsuitable for Screening Libraries, Partitioned into Those That We Also Removed and Some That We Chose Not to Remove during the Establishment of the Inaugural 2003 93K WEHI HTS Library

alkyl halides, acid halides, alkyl sulfonates, anhydrides, peroxides, isocyanates, triflates, positively charged carbon/halogen/phosphorus/
sulfur, any heterohalide, carbodiimide, acyl cyanides, sulfonyl cyanides, disulfides, thiols, epoxides, aziridines, betalactones,
betalactams, labile esters, aldehydes, certain imines, phosphate/sulfate/phosphonate/sulfonate esters, reactive michael acceptors,
ketenes, oxoniums, carbamic acids, boronic acids, primary hydrazines/oxyamines, P-N, P-S, cyclohexadienes, activated sulfonyl
(hetero)aryl halides, fluoropyridines, nitro not removed aminothiophenes, ketones, esters, hydrazones, oximes, thiocarbonyl, thioethers, $\alpha, \beta$-unsaturated amides, azo, anilines, quinones, catechols

interactions, and whole cells. However, there are significant numbers of false positives that continue to incur a resource penalty. We are currently expanding our screening library to 250000. In so doing, we wished to incorporate selection criteria built on the knowledge garnered from previous HTS campaigns. In particular, we wanted to develop substructure filters that efficiently encoded for problematic compounds in order to exclude these and their analogues from the pending bulk purchase.

We reveal herein the results of our analysis and the problematic structural classes that we have identified. We show that these compounds are prevalent in the screening literature and often painted as valid development starting points. However, we conclude that they are probably protein-reactive and poor drug development choices. Finally, we fully disclose our structural filters in readily transferable Sybyl line notation (sln) for others to utilize.

\section{Results}

The data from six HTS campaigns were selected for analysis (SI Table S2). All HTS campaigns discussed in this paper displayed an acceptable signal-to-noise ratio as judged by the $Z^{\prime}$ values ${ }^{17}$ being greater than 0.5 in each assay event. The six HTS campaigns we selected employed AlphaScreen technology (PerkinElmer), which we have found to be particularly robust and reproducible. In these campaigns, rigorous compound triaging through counterscreens, secondary screens, and finally direct binding assessment by surface plasmon resonance is routinely undertaken. However, for the purposes of this current study, we deliberately selected the primary hit set (single point inhibition) as that which represented the least-processed set for each assay. Rather, we controlled for experimental aberration through the use of multiple (six) sets of primary screening hits. Primary hit selection criteria are given in SI Table S2. We interrogated the primary screening hits as follows. All library compounds were binned according to the number of assays in which they registered as hits according to those criteria for each particular assay. As a general rule, compound screening concentrations of between 10 and $30 \mu \mathrm{M}$ were deployed. The results are shown in Table 2.

It can be seen that, reassuringly, the majority of the library compounds are clean, with 73164 registering a score of 0 and a further 12077 only registering as a hit in one assay event. However, there are 7972 compounds that hit two or more assays, of which 2062 hit four or more. The latter in particular are clearly potentially highly problematic and form the basis on which we derived our assay interference substructure filters. We wished to define substructures that selectively recognized the most problematic compounds in well-defined classes. These would form the basis of filters when selecting vendor compounds for our library expansion. To rationally achieve this, we needed to define first when a compound was considered problematic and second how we
Table 2. Breakdown of Primary Screening Hits According to the Number of HTS Screening Campaigns in Which They Registered As a Hit

\begin{tabular}{ccccccccc}
\hline & \multicolumn{6}{c}{ count $^{a}$} \\
\cline { 2 - 7 } & 6 & 5 & 4 & 3 & 2 & 1 & 0 & total \\
\hline no. compds & 362 & 785 & 915 & 1220 & 4689 & 12077 & 73164 & 93212 \\
\hline${ }^{a}$ Number of assays hit (out of six possible).
\end{tabular}

would quantify selective removal of a problematic class, that is, to define what an acceptable number would be of clean compounds that might be concomitantly removed by a substructure filter intended to remove problematic compounds.

For the first requirement, we analyzed all validated hits (i.e., true and confirmed specific binders) from around 30 target-based HTS campaigns in order to find that which happened to also register as a hit in the greatest number (if any) of the six HTS campaigns under scrutiny here. We found that one of these gave inhibition readouts of $74 \%, 58 \%$, $81 \%$, and $67 \%$ in HTS campaigns A, B, D, and E, respectively. For campaigns $\mathrm{C}$ and $\mathrm{F}$, inhibition was measured at $<50 \%$, i.e., below that which would define a compound as a hit. A screening concentration of test compound of $50 \mu \mathrm{M}$ was used for all HTS campaigns except for HTS campaign D, where the relevant concentration was $25 \mu \mathrm{M}$ (see SI Table S3). Limited investigation using surface plasmon resonance suggested that this compound had a tendency to bind nonspecifically to proteins (data not shown). Conversely, this compound was found to bind reversibly and specifically to another target of interest to us (not discussed here) with an $\mathrm{IC}_{50}$ of around $10 \mu \mathrm{M}$. This compound was subsequently optimized to single digit nanomolar levels of activity to this same target. The point of this discussion is to illustrate that an optimizable screening hit may also weakly interfere in other assays under our screening conditions. We do not attribute a high assay interference rate to the assay technology because, under our optimized conditions (see SI Table S2), our experience is that the AlphaScreen platform performs favorably compared with other platforms such as fluorescence polarization (FP). Rather, a high assay interference rate is better attributed to the relatively high screening concentrations $(25-50 \mu \mathrm{M})$ that we are prepared to employ, governed by the philosophy that weaker hits are acceptable if small and highly optimizable. We did not want to be so harsh in our definition of a problematic compound that we also removed potentially useful or proven screening hits.

These considerations finally led to the definition that a problematic compound was that with a count of 4 or more and whose target inhibition was greater than $85 \%$ in at least one HTS campaign or greater than $80 \%$ in at least two HTS campaigns, at the screening concentration tested. It is not clear to us that there is any statistically validated or less arbitrary alternative to define a cutoff point for when a compound is considered to be problematic. 
It is of course possible that some potentially useful compounds could still fall under our definition of a problematic compound and therefore be inappropriately recognized by our filters: for example, dyes that simply interfere with the assay readout technology but could in principle bind the right target protein potently and selectively, should that protein target be screened against, or compounds like our proven hit in SI Table S3 that can bind weakly but in a specific manner to several different proteins but that could be rendered selective for any given protein with appropriate optimization (somewhat akin to fragment screening). However, we were comfortable that our cutoff criteria would identify predominantly nuisance compounds and that the benefits of this would outweigh the drawbacks associated with the potential loss of a useful hit.

To start defining substructure filters, we initially scrutinized the 362 most problematic structures that hit all six assays and were able to group them into around 30 broad classes (see SI Table S4). We selected half a dozen of the most readily defined and recognizable substructures, such as quinones, rhodanines, and 2-aminothiophenes, filtered these out from our library and analyzed the counts. We did likewise for six benign moieties such as the amide group that we saw as unlikely to be linked to assay interference chemistry. We observed a stark contrast between the two classes when we totalled the number of compounds in the filtered set that hit two to six assays and expressed this as a percentage of those that were clean in the same filtered set. Whereas the values of the former ranged from 41 to $625 \%$, the latter ranged from 8 to $18 \%$, similar to the WEHI library $(11 \%$, calculated from Table 2$)$. These data are summarized in Table 3 and the data more fully disclosed in SI Table S5.

On this basis, we defined that any given substructure filter encoded acceptably for problematic compounds if, from those compounds recognized by the filter and removed, the proportion of compounds that hit two to six assays was greater than $30 \%$ of those that were clean. We term this our enrichment value.

In this way, we continued to evaluate all problematic structures, augmenting substructural descriptions or defining new ones, until all problematic compounds were accounted for in recognition filters. Toward the end we observed that

Table 3. Comparison Showing the Greater Proportion of HTS Campaigns Hit by Problematic Compounds than Clean Compounds

\begin{tabular}{llc}
\hline category & \multicolumn{1}{c}{ substructure } & $\begin{array}{c}\text { proportion hitting 2-6 } \\
\text { screens compared with } \\
\text { those hitting no screens (\%) }\end{array}$ \\
\hline clean & amide & 8 \\
clean & 2-aminopyridine & 10 \\
clean & benzothiazole & 14 \\
clean & chlorophenyl & 11 \\
clean & aromatic N & 16 \\
problematic & rhodanine-like & 41 \\
problematic & 2-aminothiophene & 43 \\
\hline
\end{tabular}

considerable numbers of singletons began to appear. In the first instance, we did not evaluate the enrichment value of individual substructure filters but simply targeted $30 \%$ as the required overall enrichment value.

The effect of passing our resulting alpha filters through our library is shown in Table 4 and as initially aimed for the enrichment value $(32 \%)$ exceeded our target of $30 \%$.

In the next phase of filter refinement, we analyzed individual substructure filters to ensure that each of these selectively removed problematic compounds according to our enrichment target value of $30 \%$. We did this as follows. We took all substructure filters from our alpha analysis that encoded for 150 compounds or more in the one family (filter family A) and assessed each of these for their enrichment value. We subsequently removed any of those substructure filters from further consideration where the enrichment value was below $25 \%$. For all others, we compared clean structures with problematic structures and rationally revised each substructure filter so that enrichment was maximized to the best of our ability and was at least $30 \%$. We then partitioned our library by removing from further consideration all compounds that were encoded in this filter family A. We then repeated the same procedure for all substructure filters that encoded between 15 and 149 compounds (filter family B) and subsequently all those that encoded 1-14 compounds (filter family C). In this way, some groups that we had initially identified as potentially problematic turned out not to be. For example, 2-alkenylfurans are conspicuous in the most problematic compounds in SI Table $\mathrm{S} 4$ but are not themselves problematic. Likewise, sulfur is prevalent in frequent hitters but only is problematic in the context of specific functional groups.

The effect of passing this, our refined filter, through our library is shown in Figure 1. Here, it can be seen that filter family A removes 4703 compounds, filter family B 2196 compounds, and filter family C 1186 compounds.

In Table 5, is it seen that while in total 480 substructures were required to filter out all assay interference compounds, the majority of these compounds (4703, filter family A) are encoded by only 16 substructures, and a further 2196 are encoded by 55 substructures (family filter B). However, 409 substructures in family filter C only account for 1186 compounds in total.

These refined filters are fully provided in the SI. Each filter family is provided as a separate text file of substructure definitions (SI Tables S6-S8). Substructures are written in Sybyl line notation (sln) and so are Sybyl-ready for the dbslnfilter algorithm. We also provide these graphically as 2D structures, grouped according to structural class (SI Figure S1) as broadly defined by the name given to each substructure. We also provide the count and enrichment calculation in SI Table S9 for each of the 174 individual substructure filters whose family size contains four or more compounds.

The effect of passing our refined filters through our compound library are shown in Table 6.

Table 4. Effect of Filtering the Inaugural WEHI-Bio21 HTS Library through the Alpha Version of Our Filters

\begin{tabular}{|c|c|c|c|c|c|c|c|c|c|}
\hline & \multicolumn{8}{|c|}{$\operatorname{count}^{a}$} & \multirow[b]{2}{*}{ enrichment $^{b}(\%)$} \\
\hline & 6 & 5 & 4 & 3 & 2 & 1 & 0 & total & \\
\hline $\begin{array}{l}\text { no. of compds in problematic } \\
\text { compds file }\end{array}$ & 362 & 785 & 809 & 835 & 2094 & 3846 & 15157 & 23888 & 32 \\
\hline $\begin{array}{l}\text { no. of compds } \\
\text { retained }\end{array}$ & 0 & 0 & 106 & 385 & 2595 & 8233 & 58005 & 69324 & 5.3 \\
\hline total & 362 & 785 & 915 & 1220 & 4689 & 12079 & 73162 & 93212 & \\
\hline
\end{tabular}

\footnotetext{
${ }^{a}$ Number of assays hit (out of six possible). ${ }^{b}$ The number of compounds that hit between two and six assays expressed as a percentage of those that hit
} no assays. 


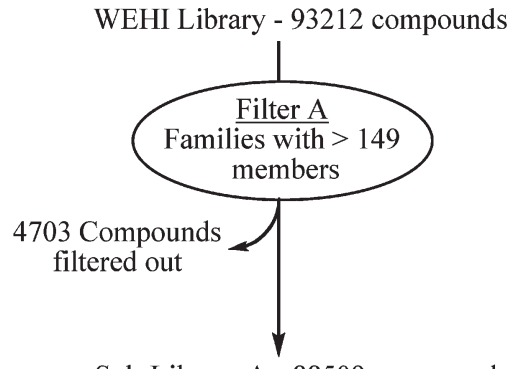

Sub-Library A - 88509 compounds

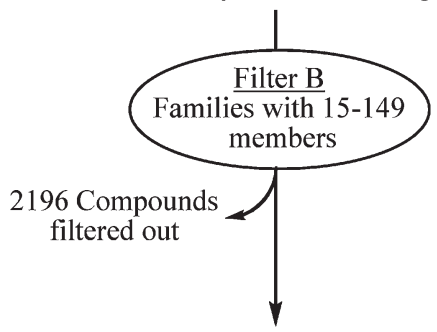

Sub-Library B - 86313 compounds

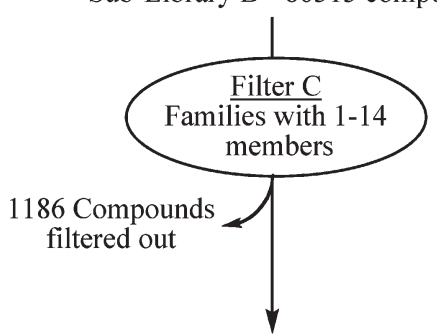

Clean Library - 85127 compounds

Figure 1. Schematic effect of passing our filter families through the WEHI 93K HTS library.

Table 5. Number of Substructures Required to Remove All Problematic Compounds and Number of Compounds Per Substructure

\begin{tabular}{cccc}
\hline grouping & $\begin{array}{c}\text { no. of compds per } \\
\text { substructure filter }\end{array}$ & $\begin{array}{c}\text { no. of substructures } \\
\text { in filter family }\end{array}$ & $\begin{array}{r}\text { no. of compds } \\
\text { (duplicates) }^{a}\end{array}$ \\
\hline filter family A & $>149$ & 16 & $4703(230)$ \\
filter family B & $15-149$ & 55 & $2196(52)$ \\
filter family C & $1-14$ & 409 & $1186(6)$ \\
\hline
\end{tabular}

${ }^{a}$ Duplicates represent those compounds that contain more than one problematic substructure.

Here, it is clear by looking at the relative enrichment levels in the clean and problematic compounds that substantial improvement has been made over our alpha filters (Table 4), with substantially fewer clean compounds present in the problematic compounds file, leading to an enrichment value of $110 \%$. There is much hidden information in these data. For example, while compounds with counts of $1-3$ did not feature whatsoever in our filter definition process, they are selectively recognized by the problematic compound filters: in the problematic file the percentage of compounds with a count of 3 relative to those with a count of 1 or 0 is $40 \%$ and $17 \%$, respectively. The corresponding figures for the clean file are $6.2 \%$ and $1.7 \%$, respectively. While a compound with a count of 3 is relatively clean by our criteria, such compounds are relatively enriched in the problematic compound file. By definition, compounds in the problematic compound file must be closely related to one or more compounds that are hits in 4 or more HTS campaigns. In other words, a relatively clean hit with a count of 3 is more plausibly a genuine hit if not recognized by our problematic compound filters. This is a useful tool for prioritizing hits from our HTS library.
Table 6. Breakdown of Primary Screening Hits According to the Number of HTS Screening Campaigns in Which They Registered As a Hit, Divided into the Filtered File (Problematic Compounds) and Those Retained

\begin{tabular}{|c|c|c|c|c|c|c|c|c|c|}
\hline & \multicolumn{8}{|c|}{$\operatorname{count}^{a}$} & \multirow[b]{2}{*}{$\begin{array}{c}\text { enrichment }{ }^{b} \\
(\%)\end{array}$} \\
\hline & 6 & 5 & 4 & 3 & 2 & 1 & 0 & total & \\
\hline $\begin{array}{l}\text { no. of compds } \\
\text { in problematic } \\
\text { compds file }\end{array}$ & $c^{362}$ & 785 & 724 & 552 & 1104 & 1372 & 3186 & 8085 & 110 \\
\hline $\begin{array}{l}\text { no. of compds } \\
\text { retained }\end{array}$ & 0 & 0 & 191 & 668 & 3585 & 10707 & 699768 & 85127 & 5.1 \\
\hline total & 362 & 785 & 915 & 1220 & 4689 & 12079 & 731629 & 93212 & \\
\hline
\end{tabular}

${ }^{a}$ Number of assays hit (out of six possible). ${ }^{b}$ The number of compounds that hit between two and six assays expressed as a percentage of those that hit no assays.

Table 7. Percentages of Compounds in a Variety of Compound Collections That Are Recognized by Our Filters for Problematic Compounds

\begin{tabular}{|c|c|c|c|}
\hline entry & compd collection & $\begin{array}{l}\text { no. of } \\
\text { compds }\end{array}$ & $\begin{array}{l}\text { problematic } \\
\operatorname{compds}^{a}(\%)\end{array}$ \\
\hline & WEHI 93K library $^{b}$ & & \\
\hline 1 & vendor A (historical/combinatorial) & 36370 & 13 \\
\hline 2 & vendor B (historical/combinatorial) & 35606 & 9.6 \\
\hline 3 & vendor C (custom-made) & 13408 & 4.0 \\
\hline \multirow[t]{2}{*}{4} & vendor D (custom-made) & 14893 & 6.0 \\
\hline & MDDR 2008.1 & & \\
\hline 5 & biological testing & 169066 & 5.1 \\
\hline 6 & preclinical & 11645 & 5.8 \\
\hline 7 & phase I & 931 & 4.8 \\
\hline 8 & phase II & 1372 & 4.2 \\
\hline 9 & phase III & 415 & 3.4 \\
\hline \multirow[t]{2}{*}{10} & launched & 1808 & 5.0 \\
\hline & other marketed drugs & & \\
\hline 11 & AMH $2008^{c}$ & 743 & 6.5 \\
\hline 12 & $\begin{array}{l}\text { CNS set }^{d} \\
\text { independent library }\end{array}$ & 142 & 2.8 \\
\hline 13 & AlphaScreen primary hit set ${ }^{e}$ & 5237 & 51 \\
\hline 14 & $\begin{array}{l}\text { WEHI HTS campaigns primary hit set } \\
\text { campaign A }\end{array}$ & 3006 & 68 \\
\hline 15 & campaign $\mathrm{B}$ & 4086 & 53 \\
\hline 16 & campaign $\mathrm{C}$ & 3145 & 72 \\
\hline 17 & campaign D & 746 & 81 \\
\hline 18 & campaign E & 9,309 & 33 \\
\hline \multirow[t]{2}{*}{19} & campaign $\mathrm{F}$ & 14,745 & 28 \\
\hline & current vendors (June 2009) & & \\
\hline 20 & vendor A & 1165361 & 4.6 \\
\hline 21 & vendor B & 239674 & 8.7 \\
\hline 22 & vendor D & 61623 & 4.6 \\
\hline 23 & vendor $\mathrm{E}$ & 207573 & 6.5 \\
\hline 24 & vendor $\mathrm{F}$ & 619514 & 5.2 \\
\hline 25 & vendor $\mathrm{G}$ & 392499 & 11.6 \\
\hline 26 & vendor $\mathrm{H}$ & 289,552 & 5.0 \\
\hline 27 & vendor I & 449998 & 10.8 \\
\hline 28 & vendor $\mathbf{J}$ & 193379 & 8.2 \\
\hline
\end{tabular}

${ }^{a}$ Those in total filtered out by filter families A-C. ${ }^{b}$ There are 100277 compounds in total arising from 7065 duplicate compounds. ${ }^{c}$ Australian Medicines Handbook (2008). ${ }^{d}$ A set of proprietary CNS active compounds. The compounds filtered out were thiothixene, amitriptyline, nortriptyline, and frovatriptan. ${ }^{e}$ Primary hits from screening a collaborator's library. ${ }^{f}$ Vendors A, B, and D (respective entries 20, 21, and 22) correspond to the same respective vendors A, B, and D for the WEHI 93K HTS library (respective entries 1, 2, and 4).

We were interested in the relationship of compound source to problematic compounds. Shown in Table 7 are the results of processing a number of different compound collections. First, we show that the source of our library compounds does influence the percentage of problematic compounds; the vendors that represent historical and combinatorial collections 


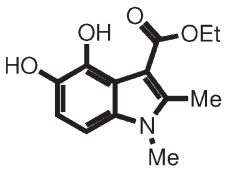

1 (WEHI-14937)

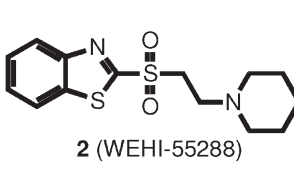

2 (WEHI-55288)

meYr

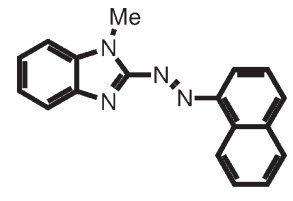

4 (WEHI-64964)
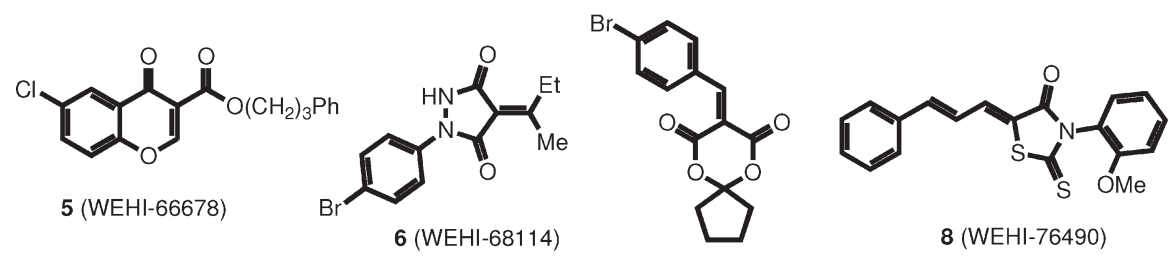

8 (WEHI-76490)

7 (WEHI-73081)

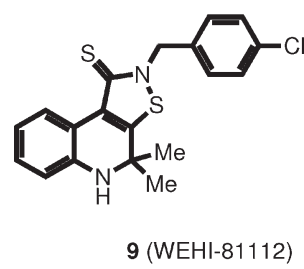

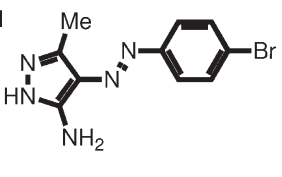

10 (WEHI-91312)

9 (WEHI-81112)

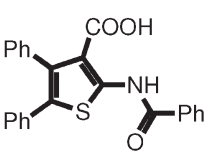

11 (WEHI-96605)

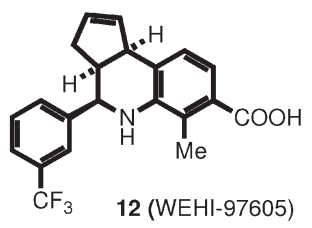

12 (WEHI-97605)

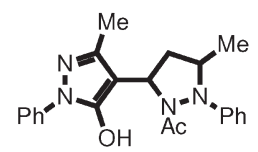

13 (WEHI-98650)

Figure 2. Problematic cul de sac compounds that have incurred wasted resources through being followed up to varying degrees at our Institute. We have found chromones such as $\mathbf{5}$ to be highly susceptible to nucleophilic attack at the 2-position, while $\beta$-amino sulfones (and ketones) such as 2 readily form reactive retro Michael alkenes. Compounds $\mathbf{6}-\mathbf{9}$ are also susceptible to attack by biologically relevant nucelophiles. The other compounds are problematic for reasons that are either discussed in the text or remain unknown.

tend to contain a greater proportion of problematic compounds. Hence, the percentages here are $13 \%$ and $9.6 \%$ for vendors $\mathrm{A}$ and $\mathrm{B}$, respectively, compared with $4 \%$ and $6 \%$ for vendors $\mathrm{C}$ and $\mathrm{D}$. The latter vendors describe their approach to library design as being more tailor-made than combinatorial, suggesting a link with problematic compounds and facile chemistry.

We also analyzed MDDR 2008.1, and here it is clear that a continuous percentage of compounds register as problematic compounds from preclinical to launched categories without apparently trending upward or downward. Similarly, 48 compounds (6.5\%) out of 743 from the Australian Medicines Handbook (2008) are recognized by our problematic compound filters. These percentages are, however, relatively small and similar to those noted in tailor-made vendor libraries. Prevalent in these compounds are quinones/acridine-based cytotoxics, but there are also neuroleptics, dopamine-like catechols, and occasional steroids, dyes, and phenylmorpholines (see SI Figure S2).

A set of CNS compounds revealed only four $(2.8 \%)$ as being recognized by our problematic compound filters (entry 12).

To ascertain that assay interference compounds recognized by our filters were not peculiar to our library, we tested the effect of passing our filters through another primary hit set that we had obtained from a primary screen of a commercial collaborator's HTS library using AlphaScreen technology. As shown in Table 7 (entry 13), in marked contrast to drug-like compounds, this screening library primary hit set registered a substantial number of compounds $(51 \%)$ as being recognized by our problematic compound filters.

We also passed our filters back through our original primary hit sets from the six HTS campaigns under investigation here (SI Table S2), and as shown in Table 7, as would be hoped, a large percentage of primary hits are removed by our filters, the highest being $81 \%$ for HTS campaign D (entry 17 ). The two lowest percentages of $33 \%$ and $28 \%$, respectively, are represented by HTS campaigns $\mathrm{E}$ and $\mathrm{F}$, which used a different anchoring technology, causing a high hit rate with dilution of the primary screening set due to interference by mildly chelating compounds (see SI Table S2).

Finally, we passed our filters through the databases of nine popular current vendors. Also shown in Table 7, the percentage of problematic compounds varies from a low of $4.6 \%$ for vendor A (entry 20) to a significant high of $11.6 \%$ for vendor G (entry 25). Intriguingly, vendor A in 2003 contained a significantly higher percentage of these problematic compounds $(13 \%$, entry 1$)$, suggestive of a deliberate effort to minimize the numbers of such compounds.

Significantly, our filters would have removed problematic compounds shown in Figure 2 that have incurred significant costs through some medicinal chemistry follow up that ultimately failed due to the lack of robust SAR. We term these cul de sac compounds. We note that these compounds often showed signs of early SAR and selectivity when tested in appropriately designed counter screens so that we embarked 
on limited follow-up despite reservations about some of the structures. This point will be raised again later.

Finally, we then deployed our filters for the establishment of a new HTS library that ultimately comprised 136203 compounds, which we term the CTX 136K HTS library. Apart from the additional use of our assay interference filters, similar selection criteria were used as before for the inaugural WEHI 93K HTS library. These are summarized in Table 8. We also used a similar, but slightly expanded, filter for inappropriate functional groups as before (see SI Table S1).

Because of time constraints, we used our alpha version of the filters in establishing the CTX 136 HTS library. We also collaborated with Professor Paul Wyatt (University of Dundee) on the purchase of a separate library of 15667 compounds, which we term the CTX 16K HTS sub-library,

Table 8. Selection Criteria Used for Lead-Like CTX 136K HTS Library and Some Simple Statistics on the Resulting Library

\begin{tabular}{|c|c|}
\hline property & selected range (average) \\
\hline molecular weight & $150-450(351)$ \\
\hline maximum number of rings & $4(3)$ \\
\hline minimum number of rings & 1 \\
\hline maximum cLogP & $5(2.9)$ \\
\hline $\begin{array}{l}\text { maximum number of } \\
\text { freely rotatable bonds }\end{array}$ & $10(5)$ \\
\hline $\begin{array}{l}\text { maximum number of } \\
\text { chiral centers }\end{array}$ & 3 \\
\hline $\begin{array}{l}\text { maximum number of } \\
\text { hydrogen bond donors }\end{array}$ & 5 \\
\hline $\begin{array}{l}\text { maximum number of } \\
\text { hydrogen bond acceptors }\end{array}$ & 8 \\
\hline $\begin{array}{l}\text { minimum number of } \\
\text { hydrogen bond acceptors }\end{array}$ & 1 \\
\hline $\begin{array}{l}\text { average polar surface } \\
\text { area }\left(\AA^{2}\right)\end{array}$ & 67 \\
\hline
\end{tabular}

bringing the total number of compounds to 152795 compounds, which we term the CTX 153K HTS library. For the reader interested in an analysis of functional group prevalence in these and other compound libraries, a task that we are not aware of having been undertaken in the literature, we refer them to Table S10 in the SI.

\section{Discussion}

To consider why compounds may be problematic in our HTS campaigns, we need to understand the underpinning technology, this being the AlphaScreen assay. This is shown schematically in Figure 3.

Typically, multiple copies of biotinylated protein (protein A here) are bound to streptavidin-coated donor beads, while multiple copies of the GST-fusion protein partner (protein B here) are bound to GST-Ab-coated acceptor beads. On incubation, the donor beads bind to acceptor beads via multiple interactions between the protein partners. Upon excitation at $680 \mathrm{~nm}$, donor beads release singlet oxygen, which reacts with thioxene-based groups on the nearby acceptor bead. This triggers energy transfer of 340-350 nm to anthracene-based groups, resulting in further energy transfer of 450-500 $\mathrm{nm}$ to rubrene-based groups also on the acceptor bead, finally resulting in emission at $520-620 \mathrm{~nm}$, which is detected as the readout. In the presence of an inhibitor of the protein-protein interaction, the donor beads are not bound to the acceptor beads and remain relatively far apart from each other, such that the unstable singlet oxygen decomposes before being able to react with the acceptor beads. Hence, a positive readout from this assay is a loss of signal.

A false positive signal could conceivably arise via several mechanisms: (i) compounds that absorb light at these relevant wavelengths, but in particular the excitation wavelength of

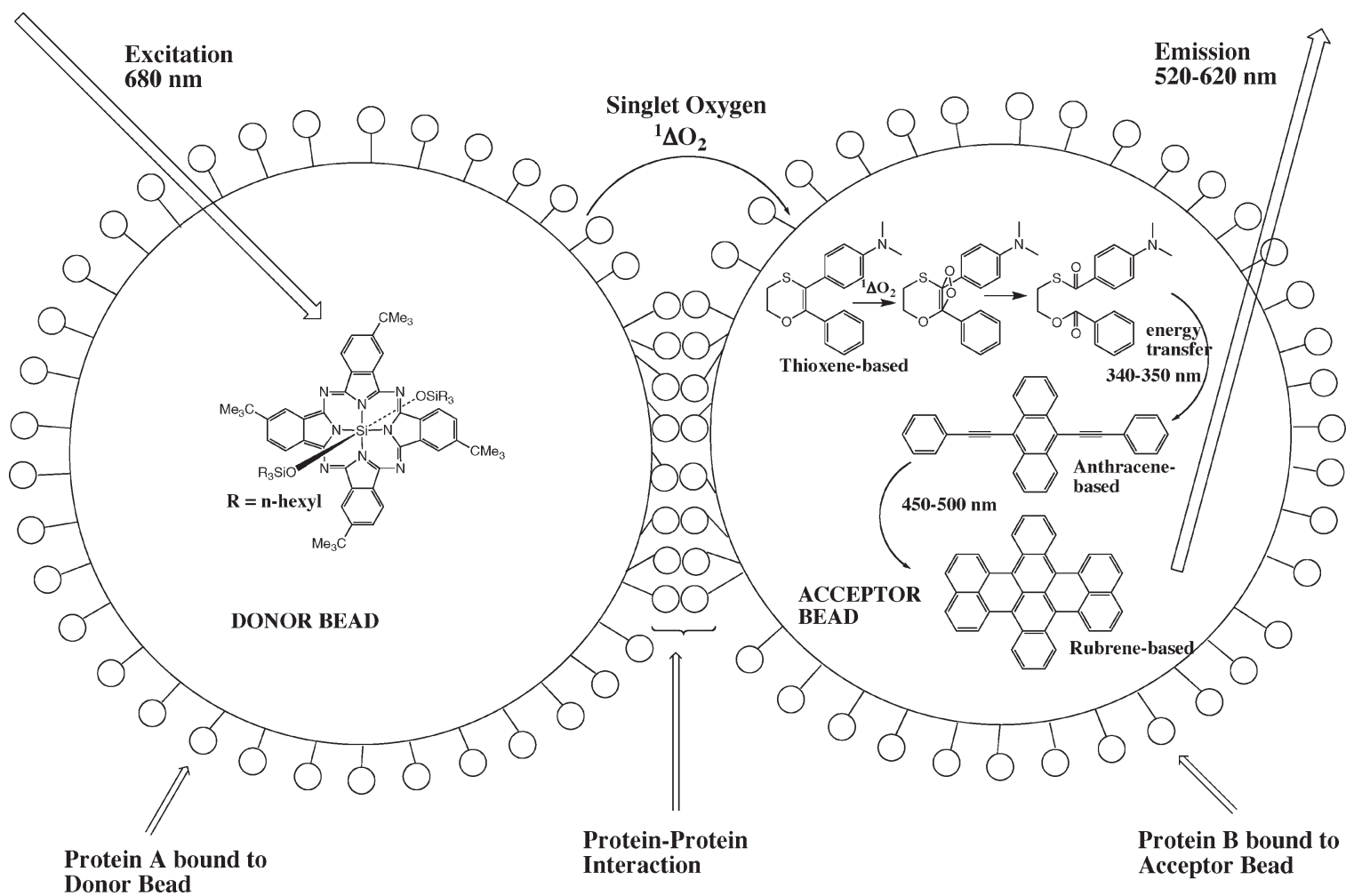

Figure 3. Schematic depiction of the physical chemistry underpinning AlphaScreen assay technology. 
$680 \mathrm{~nm}$ or the emission wavelength of $520-620 \mathrm{~nm}$; (ii) compounds that react with singlet oxygen; (iii) compounds that were not identified by the reactive functional group filter and can covalently bind to proteins; (iv) compounds that are inherently "sticky" and can bind to many sites on proteins; (v) compounds that form aggregates. ${ }^{2-5}$ Here, relevant proteins include not just those being interrogated in the assay but also the linking antibodies. With respect to points (iv) and (v), we note that we include both a detergent (Tween-20,0.05\%) and casein $(0.1 \mathrm{mg} / \mathrm{L})$ in our optimized assay conditions to minimize these phenomena (see SI Table S2).

As a simple test of the sensitivity of this technology to the first two mechanisms, we tested a range of dyes that absorb at wavelengths from $400 \mathrm{~nm}$ (quercetin) to $618 \mathrm{~nm}$ (Chicago sky blue). We deliberately included methyl orange, a dye that

Table 9. Activity of Dyes and Singlet Oxygen Quenchers in the AlphaScreen Assay

\begin{tabular}{|l|l|}
\hline Compound & $\mathrm{IC}_{50}(\mathrm{n}=6)$ \\
\hline Quercetin (400 nm - Yellow) & $>100 \mu \mathrm{M}$ \\
\hline Tartrazine (425 nm - Yellow) & $>100 \mu \mathrm{M}$ \\
\hline Fluorescein (496 nm - Yellow) & $>100 \mu \mathrm{M}$ \\
\hline Methyl Orange (507 nm) & $53 \pm 5 \mu \mathrm{M}$ \\
\hline Cytochrome C (550 nm - Orange-Pink) & $>100 \mu \mathrm{M}$ \\
\hline Trypan Blue (607 nm) & $8 \pm 0.2 \mu \mathrm{M}$ \\
\hline Malachite Green (615 nm) & $3 \pm 0.5 \mu \mathrm{M}$ \\
\hline Chicago Sky Blue (618 nm) & $3 \pm 0.5 \mu \mathrm{M}$ \\
\hline DABCO & $65 \pm 1 \mu \mathrm{M}$ \\
\hline Diazobenzene (tangerine color in solution) & $65 \pm 10 \mu \mathrm{M}$ \\
\hline & \\
\hline & \\
\hline
\end{tabular}

absorbs at $507 \mathrm{~nm}$, but that is also a well-known singlet oxygen quencher. ${ }^{18,19}$ In the latter capacity, we also included DABCO, a strong singlet oxygen quencher which is devoid of a chromophore, and diazobenzene itself. The results are shown in Table 9.

Hence it is clear that while the AlphaScreen assay is relatively robust to interference by several dyes, compounds that absorb light in the range 576-620 nm interfere quite strongly with apparent $\mathrm{IC}_{50}$ values of between 3 and $8 \mu \mathrm{M}$. These compounds are colored either red, green, or blue. We propose that the assay interference by methyl orange is due to reaction with singlet oxygen and not absorption of light at $507 \mathrm{~nm}$ because it resides within the absorption range of other noninterfering dyes. Its inhibitory activity is similar to that of DABCO and diazobenzene. However, both are relatively weak interference compounds with apparent $\mathrm{IC}_{50}$ values of 53 and $85 \mu \mathrm{M}$, respectively. The AlphaScreen assay would thus appear to be relatively robust toward singlet oxygen quenchers.

A small proportion of our screening compounds are highly colored, and it is highly plausible that these could photometrically interfere in our assays. However, with very few exceptions, we find that no problematic class is dominated by compounds of such colors. Also, with very few exceptions, no problematic class hits exclusively hits all six AlphaScreen campaigns (see SI Table S9). This point is relevant because compounds that interfere colorimetrically such as those in Table 9 (sulforhodamine, trypan blue, malachite green, Chicago sky blue) invariantly return the $\mathrm{IC}_{50}$ values as listed for every AlphaScreen assay undertaken. This leaves mechanisms (iii-v) as alternative ways that compounds could interfere with our biological assays. To test this hypothesis, we analyzed the results from a recent HTS campaign that used both the inaugural WEHI 93K HTS library as well as the new CTX 136K HTS library. Critically, this new HTS campaign deployed an unrelated assay technology, fluorescence polarization (FP), where excitation at $530 \mathrm{~nm}$ and emission at $590 \mathrm{~nm}$ were the relevant signaling wavelengths. The readout from FP is the change in the ratio of polarized light. Appropriately colored compounds could quench the signal but are unlikely to change this ratio and FP false positives arise more commonly from compounds that are fluorescent, the FP false positive hit rate consequently being quite high (AlphaScreen assays are run in such a way that short-term fluorescence does not cause interference). The results are shown in Table 10.

Here the numbers of compounds that registered as primary hits are shown, and the attrition rate is followed as hits confirmed through retesting in the FP assay (column B) and finally tested in a secondary assay using homogenous timeresolved fluorescence (HTRF, column C). Compounds that progress all the way to reconfirm in the secondary HTRF assay are very unlikely to represent interference in signal quenching in a manner that relates in any way to AlphaScreen

Table 10. Hit Triaging through Fluorescence Polarization (FP) Primary Assay and Homogenous Time-Resolved Fluorescence (HTRF) Secondary Assay for Inhibition of DNA Binding to a DNA-Binding Protein ${ }^{a}$

\begin{tabular}{|c|c|c|c|c|}
\hline & A & B & $\mathrm{C}$ & $\mathrm{D}$ \\
\hline library & $\begin{array}{l}\text { primary FP } \\
\text { hit set }(\%)\end{array}$ & $\begin{array}{c}\text { confirmed FP } \\
\text { retest hits } \\
(\% \text { relative to } \mathrm{A})\end{array}$ & $\begin{array}{c}\text { secondary HTRF } \\
\text { hit set }(\% \text { relative to } \mathrm{B})\end{array}$ & filters $^{b}$ \\
\hline 2003 WEHI 93K & $941(1.0 \%)$ & $198(21 \%)$ & $50(25 \%)$ & 10 \\
\hline 2008 CTX 136K & $166(0.12 \%)$ & $80(48 \%)$ & $37(46 \%)$ & 37 \\
\hline
\end{tabular}

\footnotetext{
${ }^{a}$ Hit criteria: $>30 \%$ inhibition at $25 \mu \mathrm{M}$ for WEHI $93 \mathrm{~K}$ and $>30-50 \%$ inhibition at $12.5 \mu \mathrm{M}$ for CTX $136 \mathrm{~K} .{ }^{b}$ Number of compounds left after
} passing our refined filters through the secondary hit set. 
technology. Despite this, when we pass our AlphaScreen assaybased filters through the secondary confirmed hits arising from the WEHI 93K HTS library, $80 \%$ of the hits are removed and only 10 compounds are left. Of course, none is removed via this process when applied to the secondary hit set arising from screening of the CTX $136 \mathrm{~K}$ library because by definition this library has been filtered free of such compounds. It is therefore likely that the $80 \%$ of hits filtered from the WEHI $93 \mathrm{~K}$ secondary hit set represent assay interference through mechanisms (iii-v) above in that they are either protein reactive, inherently sticky, or extremely prone to aggregate formation. As already mentioned, the latter two phenomena are likely to be minimized by the use of detergent and buffering protein in our assay protocol (SI Table S2), leaving protein reactivity as a possible dominant mechanism for assay interference.

Quite remarkably, the attrition rate for hit validation exhibited by the CTX 136K library is markedly lower than that for the WEHI 93K HTS library such that even starting with a smaller primary hit set (166 compared with 941), 37 validated hits are furnished compared with only 10 from the WEHI 93K HTS library (theoretically, the latter number would be 15 were the WEHI 93K library to be the same size as the CTx library and number $136 \mathrm{~K}$ compounds). The processes used to establish the CTX 136K library meant that the only difference in the hit triaging process that should be observed is that in progressing from column $\mathrm{C}$ to column $\mathrm{D}$. Instead, marked differences between the two libraries are also witnessed in progressing from columns $\mathrm{A}$ and $\mathrm{B}$ to $\mathrm{C}$. This implies that an additional beneficial effect that our filters for problematic compounds have had is to produce a library that has fewer compounds that interfere in the FP photometric readout. This was entirely unexpected. It is true that the CTX $136 \mathrm{~K}$ library was screened at half the concentration of that of the WEHI 93K library, and there was some variability in the latter HTS campaign as judged by the poor confirmation rate in $\mathrm{B}$, but this would not appear to fully account for the differences in attrition rate observed. We have no explanation for this but merely point out the significant resource saving that screening of the CTX $136 \mathrm{~K}$ library represents through the low hit validation attrition rate. ${ }^{20}$ Of course, we do not claim that this library is entirely free of protein reactive compounds, as new chemistries will not necessarily be captured by our evidence-based filters developed for compounds purchased in 2003.

Most bioassays utilize some sort of photometric readout and essentially all involve the use of proteins so that proteinreactive compounds could cause assay interference. A critical implication here is that our filters for problematic compounds may encode for pan-assay interference compounds.

Given that these compounds are still well represented in commercially available chemical collections $(5-12 \%$ as listed in Table 7, entries 20-28) and given that there has been a recent rapid expansion in academic laboratories undertaking screening, we reasoned that many others would be furnishing such compounds as screening outcomes. Given also that academic researchers may not have the depth of experience in weeding out problematic compounds that pharmaceutical companies do and that academics are constantly under constant pressure to publish, we reasoned that this collectively may be manifest in the screening-based literature. Conversely, an absence of these compound classes in the literature might suggest our findings are relevant only to our laboratory and an aberration associated with either our screening technology or the nature of targets investigated in this study, all of which are protein-protein interactions. With respect to the latter, how- ever, we note that the target topography is relatively dissimilar and that confirmed screening hits are invariably selective by at least several fold for only one target, even between two proteins that both recognize an amphipathic $\alpha$-helix.

We have consequently undertaken a literature investigation on around 15 of the most problematic compound classes that we have discovered, as defined by a combination of their enrichment value and population size. We deliberately focused on screening-based literature covering a diverse array of screening technologies and generally not AlphaScreen. This literature also covers a very wide range of biological targets, from ion channels and enzymes to other protein-protein interactions. Despite this, we show that compound classes identified as problematic in our assays correspond closely to those reported in this screening literature as assay hits. We also conclude that because of the crossover between our results and the literature, our empirical approach to the interrogation of our historical assay data for the identification of promiscuous compound classes has not resulted in outcomes relevant only to our assay technology or the nature of our targets (protein-protein interactions). Qualitative analysis of 30 other HTS campaigns undertaken over the last 5 years in our laboratories where different screening technologies and targets that included enzymes and ion channels were used supports this conclusion. Rather, we suggest that these outcomes will be of general utility. We summarize here our findings on each of these problematic compound classes. We conclude that at least 10 of these compound classes should be considered to be pan assay interference compounds, for which we have coined the acronym PAINS, and avoided as development options when furnished as screening hits. The hallmark of these compounds is confusing SAR that in a number of cases appears to track with reactivity.

Pan Assay Interference Compounds (PAINS). We have identified rhodanines, phenolic Mannich bases, hydroxyphenylhydrazones, alkylidene barbiturates, alkylidene heterocycles, 1,2,3-aralkylpyrroles, activated benzofurazans, 2-amino-3-carbonylthiophenes, catechols, and quinones as PAINS. In Table 11, their frequency of occurrence as hits in our assays is accompanied by a summary of their prevalence in the screening literature along with any literature that may be associated with mechanisms for assay interference.

A key observation to be made here is that different classes of PAINS frequently copresent in the same publication. A more extensive discussion on this, on the variety of targets involved, detail on the nature of possible mechanisms of action for each class of PAINS, and an example of typically confusing SAR (in the case of fused tetrahydroquinolines) is provided as SI (Tables S11-S21).

Putative Pan Assay Interference Compounds. There are many dozens of other compound classes that may ultimately be shown to be PAINS (see SI Tables S6-S8 and Figure S1) but for which currently there is not the body of literature to indict them as such. We briefly report on three of these that may be among the most problematic, these comprising azo, cyanopyridones, divinylketones, and certain indoles. ${ }^{174}$

These are listed in Table 12 and an extended discussion for these classes and possible mechanisms of action may be found in the SI (Tables S22-S25).

AlphaScreen-Specific Interference Compounds. Tertiary anilines are highly problematic in our assays both because of their prevalence and high enrichment values. We propose that these could be more specific to AlphaScreen technology as they are well-known potent quenchers of singlet oxygen. ${ }^{175}$ 
A key indicator here is the lack of their presence in the screening literature cited thus far, of which only one study used AlphaScreen technology. ${ }^{168}$ We provide an extended discussion in SI Tables S26 and S27.

Table 11. Pan-Assay Interference Compounds That Are Becoming Increasingly Prevalent in the Literature As Screening Hits

\begin{tabular}{|c|c|c|c|c|c|c|}
\hline Substructure $^{a}$ & Assays Hit & \# Cpds & Total Cpds & Enrichment ${ }^{b}$ & Refs for hits & Refs for $\mathrm{MOA}^{\mathrm{C}}$ \\
\hline Rhodanines & 0 & 60 & \multirow[t]{6}{*}{235} & \multirow[t]{6}{*}{$227 \%$} & \multirow[t]{6}{*}{$21-55$} & \multirow{6}{*}{$\begin{array}{l}\text { Reactivity.,7,36-40 } \\
\text { Chelation. }{ }^{22}\end{array}$} \\
\hline & 1 & 39 & & & & \\
\hline & 2 & 32 & & & & \\
\hline & 3 & 26 & & & & \\
\hline & 4 & 21 & & & & \\
\hline & 5 & 41 & & & & \\
\hline \multirow{3}{*}{\multicolumn{5}{|c|}{$\left.\right|_{S} ^{\text {Rhodanine-related }}$}} & $21.23,25.26$ & Reactivity. $^{38,39}$ \\
\hline & & & & & $\begin{array}{l}38-42,51,52 \\
55,56-77\end{array}$ & \\
\hline & & & & & & \\
\hline Phenolic mannich & 0 & 146 & 296 & $64 \%$ & $78-83$ & Reactivity $^{84,85,92}$ \\
\hline Fente & 1 & 57 & & & & Chelation. $^{86-90}$ \\
\hline & 2 & 59 & & & & Cytotoxicity. ${ }^{91}$ \\
\hline & 3 & 15 & & & & \\
\hline & 4 & 13 & & & & \\
\hline & 5 & 4 & & & & \\
\hline $\operatorname{ch} \mathrm{A}$ & 6 & 2 & & & & \\
\hline & 0 & 156 & 479 & $154 \%$ & $21,41,74,75$, & Reactivity. ${ }^{105}$ \\
\hline phenyl-hydrazone & 1 & 82 & & & 78, 91, 93-98. & Spectroscopic. ${ }^{101-102}$ \\
\hline & 2 & 208 & & & & Chelation. ${ }^{103,104}$ \\
\hline & 3 & 17 & & & Also $^{\text {d }} 30,75$ & Aggregates. $^{2}$ \\
\hline & 4 & 7 & & & 78-80, 91, 92, & \\
\hline & 5 & 4 & & & $94,99,100$ & \\
\hline $\begin{array}{c}\mathrm{N}^{\text {viv }} \\
\text { hzone }\end{array}$ & 6 & 5 & & & & \\
\hline 4-Hydroxy- & 0 & 104 & 215 & $55 \%$ & & \\
\hline phenyl & 1 & 54 & & & & \\
\hline & 2 & 38 & & & & \\
\hline & 3 & 6 & & & & \\
\hline & 4 & 9 & & & & \\
\hline $\mathrm{N}^{\mathrm{N} N}$ & 5 & 2 & & & & \\
\hline hzone phenol B & 6 & 2 & & & & \\
\hline & 0 & 228 & 483 & $66 \%$ & $23,26,29,41$, & Reactivity. ${ }^{39,115-118}$ \\
\hline barbi & 1 & 105 & & & $42,51-55,74$ & \\
\hline & 2 & 69 & & & & \\
\hline & 3 & 30 & & & & \\
\hline & 4 & 21 & & & & \\
\hline & 5 & 20 & & & & \\
\hline ene & 6 & 10 & & & & \\
\hline & 0 & 64 & 201 & $152 \%$ & $21,23,28$ & There appears to be little literature on \\
\hline & 1 & 40 & & & $40-42,45,50$ & these alkylidene bearing five-membered \\
\hline & 2 & 39 & & & $51,66,119-$ & heterocycles relevant to possible MOA. \\
\hline & 3 & 14 & & & & However, the pyrazolidin-3,5-diones \\
\hline ene fiv & 4 & 24 & & & & (ene_five_het_D), that dominate the hit \\
\hline & 5 & 14 & & & & references, are highly likely to be potent \\
\hline & 6 & 6 & & & & Michael Acceptors. We also note that \\
\hline & 0 & 44 & 90 & $55 \%$ & & the 5-alkenylimidazolin-4-one core \\
\hline & 1 & 22 & & & & (ene_5 het_G) is the chromophore in \\
\hline & 2 & 14 & & & & green fluorescent protein. ${ }^{128}$ \\
\hline & 3 & 2 & & & & \\
\hline ene five het $B$ & 4 & 4 & & & & \\
\hline & 5 & 4 & & & & \\
\hline & 6 & 0 & & & & \\
\hline & 0 & 39 & 85 & $85 \%$ & & \\
\hline & 1 & 13 & & & & \\
\hline & 2 & 7 & & & & \\
\hline & 3 & 7 & & & & \\
\hline$\underline{e n e \_f i}$ & 4 & 7 & & & & \\
\hline & 5 & 9 & & & & \\
\hline & 6 & 3 & & & & \\
\hline & 0 & 0 & 46 & na & & \\
\hline & 1 & 5 & & & & \\
\hline & 2 & 13 & & & & \\
\hline & 3 & 9 & & & & \\
\hline ene five & 4 & 8 & & & & \\
\hline ene nive nel_. & 5 & 7 & & & & \\
\hline & 6 & 4 & & & & \\
\hline & 0 & 5 & 10 & $80 \%$ & & \\
\hline & 1 & 1 & & & & \\
\hline & 2 & 1 & & & & \\
\hline & 3 & 1 & & & & \\
\hline ene five het $G$ & 4 & 2 & & & & \\
\hline & 5 & 0 & & & & \\
\hline & 6 & 0 & & & & \\
\hline & 0 & 0 & 6 & na & & \\
\hline & 1 & 3 & & & & \\
\hline & 2 & 2 & & & & \\
\hline & 3 & 0 & & & & \\
\hline ene five het $\mathrm{H}$ & 4 & 0 & & & & \\
\hline & 5 & 1 & & & & \\
\hline & 6 & 0 & & & & \\
\hline
\end{tabular}


Table 11. Continued

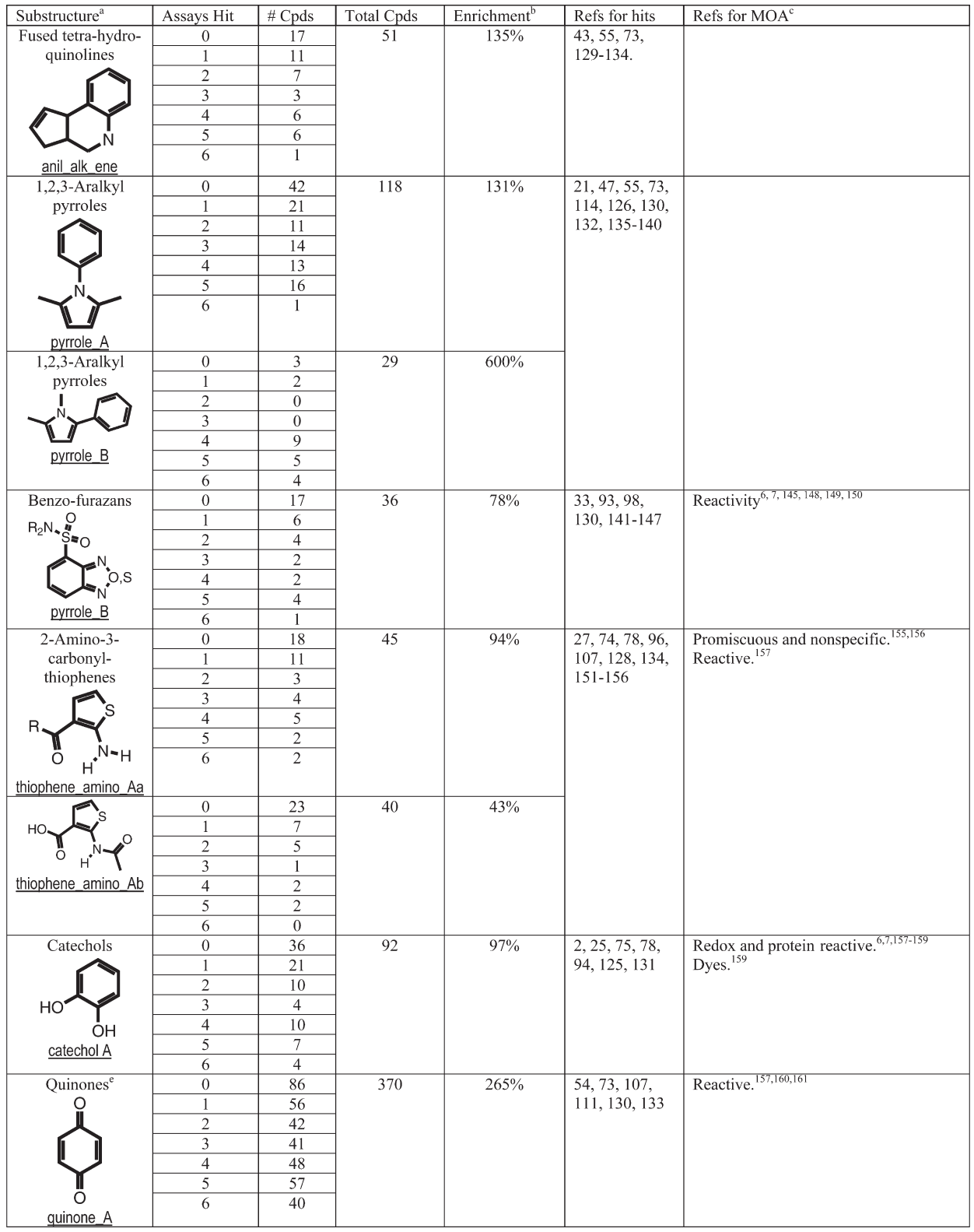

${ }^{a}$ Underscored name corresponds to name in SI Tables S6-S8 and Figure S1. ${ }^{b}$ Total number of compounds that hit from 2 to 6 assays expressed as a percentage of those compounds that have hit none of the six assays; na = not applicable (enrichment $=$ infinity because of absence of any compound that hit no assays). ${ }^{c}$ Publications describing behavior that could be directly or indirectly relevant to interference in biological assays. See SI for an extended discussion. ${ }^{d}$ Closely related 2-hydroxybenzamide-like. ${ }^{e}$ The sln definition is broader than this (see SI), but the answer set is dominated by these compounds.

Other Compounds. It is beyond the scope here to exhaustively list the large number of other putative PAINS and the literature associated with them. However, it is useful to briefly list some of the classes that we find are problematic (see Tables S6-S8 and Figure S1 in SI) and that also appear in the screening literature already cited. These include certain guanidines, ${ }^{74,96,165}$ certain 1,4-dihydropyridine-like compounds, ${ }^{26,78,99,107,119,134}$ certain isatin-like compounds, ${ }^{75}$ certain 2-amino-1,3,5-triazines, ${ }^{28,75,112,165}$ aminoacridines, ${ }^{111}$ and certain arysulfonamides (it seems unlikely that the arylsulfonamides involved would be reactive enough to form a Meisenheimer complex with protein thiols and the reasons for their appearance in these screening hit sets remains unknown). ${ }^{21-24,28,130}$ Some dye-like compounds with conjugated and often charged nitrogen atoms also appear in some of the screening literature already cited. ${ }^{74,168}$ We find that several of these also interfere in our assays, which is unsurprising considering the results shown in Table 9. We show selected and particularly pertinent examples to this discussion in Figure 4.

There are two other classes suspiciously prevalent in this screening literature already cited. These are 2-mercapto1,3,4-triazoles and their regioisomeric 2-amino-1,3,4-thiadiazoles. $^{2,25,66,73,75,78,99,108,120}$ These number several hundred in the WEHI 93K HTS library but do not register as problematic compounds. Intriguingly, these compound classes have arisen as hits in some more recent screens that we have run. It is possible that the targets involved in these subsequent screens are particularly sensitive to protein-reactive compounds and, like the Lan protein that Abbott have developed as a probe for protein-reactive compounds, will pick up potential PAINS that other targets will not. ${ }^{6,7,157} \mathrm{We}$ 
Table 12. Compounds That We Find Problematic As Screening Hits That May Be PAINS

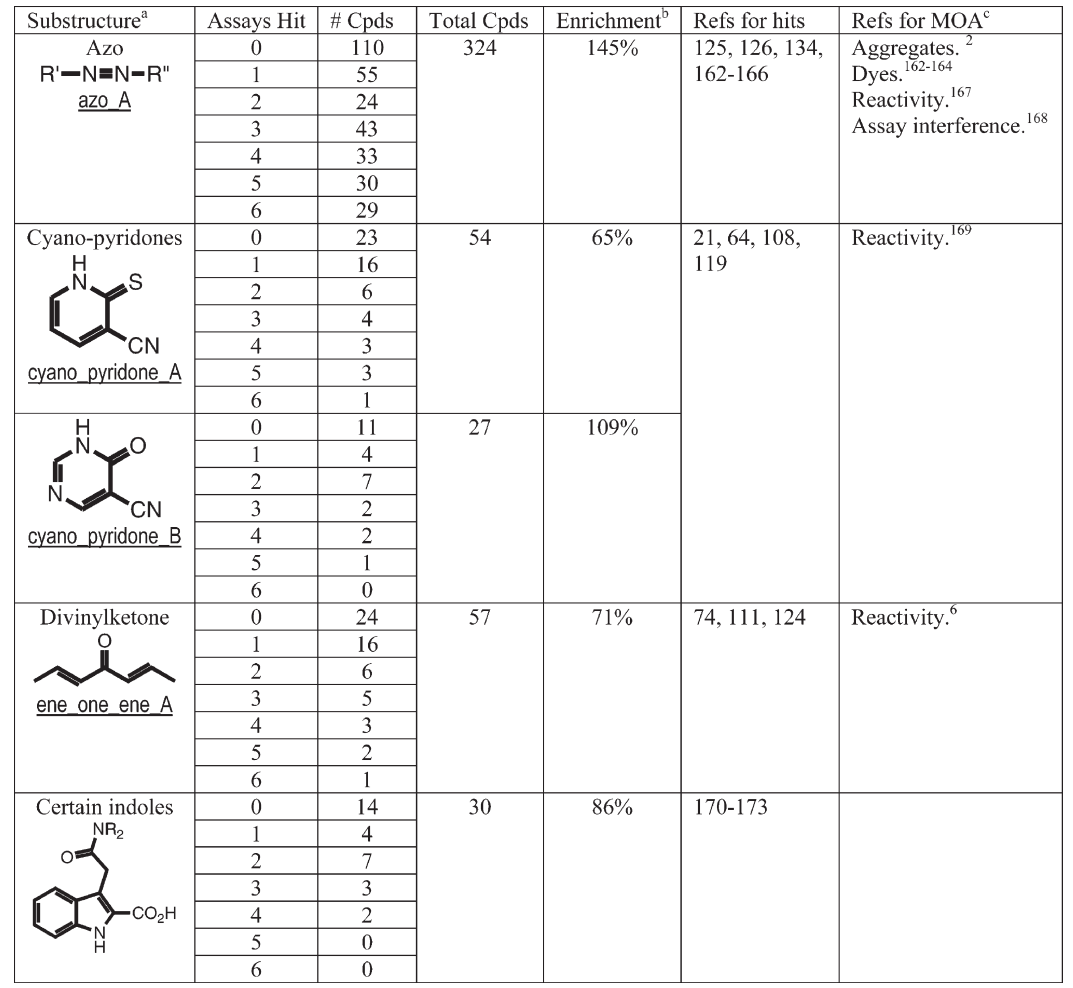

\begin{abstract}
${ }^{a}$ Underscored name corresponds to name in SI Tables S6-S8 and Figure S1. ${ }^{b}$ Total number of compounds that hit from 2 to 6 assays expressed as a percentage of those compounds that have hit none of the six assays. ${ }^{c}$ Publications describing behavior that could be directly or indirectly relevant to
\end{abstract} interference in biological assays. See SI for an extended discussion.

note related heterocycles can exhibit unusual chemical instability in solution, ${ }^{176}$ and we now filter out such compounds as we believe that many of these are prone to assay interference via mechanisms yet to be determined. We have also found that certain 2-aminothiazoles feature as problematic compounds (see SI Figure S1). This class of compounds has been found to be photoreactive, and some pharmaceutical companies refuse to progress them as screening hits (Simon Campbell, personal communication) or indeed are purging their HTS libraries of them (Ian Holmes, personal communication). We also note that Abbott find that as a class, they can be protein reactive. ${ }^{7}$ There are a number of 2-aminothiazoles in phase I (11), II (15), III (2) trials or in launched drugs (28), and we have many in our library that do not appear to be problematic at least for HTS. This may be a class where the nature of the substituents greatly modulate lead-like and drug-like properties and that certain subclasses are entirely benign while others are not. Currently, our policy is to not filter out this class for HTS but this is under current review.

The Link Between Facile Chemistry and Problematic Compounds. We suggested earlier that the greater proportion of problematic compounds in combinatorial chemistry-based vendors implicates a link between these and facile chemistry. Indeed, as shown in Figure 5, many of these compound classes are very readily assembled from simple building blocks to give rapid diversity generation.

However, amide bond formation also represents facile linkage chemistry and we have shown in Table 3 that amide-containing compounds are not associated with problematic compounds. Any link between facile chemistry and problematic compounds would appear to be that involving condensation chemistry where a product containing an exocyclic alkene is furnished that could act as
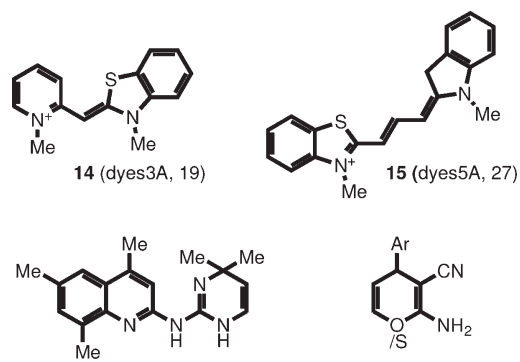

17 (het_66_B, 2)

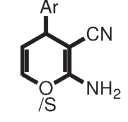

18 (dhp_amino_CN_A, 13; dhp_amino_CN_C, $\overline{7}$; dhp_amino_CN_D, 5; dhp_bis_amino_CN, 19)

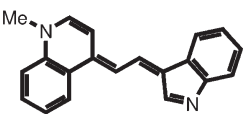

$16($ dyes $7 \mathrm{~A}, 2)$<smiles>O=C1Oc2ccccc2C1=O</smiles>

19 (imine_one_fives_B, 9 imine_one_fiivs_C, 2 ; imine_one_isatin, 189
Figure 4. Examples of other types of compounds that interfere in our assays and also appear in the screening literature. We have included the filter name by which each structure is recognized in SI Figure S1 and Tables S6-S8 along with the number of compounds that substructure corresponds to in our HTS library. Structures 14-16 are dyes. We have in total 46 of these in our WEHI 93K HTS library, which are diverse in structure and yet all are encoded by three simple filters. The integer in the file name refers to the number of carbons between the nitrogens. We note that this could be extended, and a 9-carbon-linked dye has been reported also as an assay interference compound. ${ }^{168}$ Structure $\mathbf{1 7}$ is a cyclic guanidine and precisely the same structure has been reported elsewhere ${ }^{74}$ even though we have only two examples in our WEHI 93K HTS library. Structure $\mathbf{1 8}$ encodes for a significant number of dihydropyran-like subfamilies, which we find to be problematic for reasons unknown. Similarly, structure 19 encodes for a large number of isatin-like compounds that we find problematic for reasons unknown. Both $\mathbf{1 8}$ and $\mathbf{1 9}$ are prevalent in the screening literature as discussed in the text.

a Michael acceptor. Such compounds could still be useful, however, after on-reaction to a lower energy product, such as that shown by way of illustration in Figure 6. 


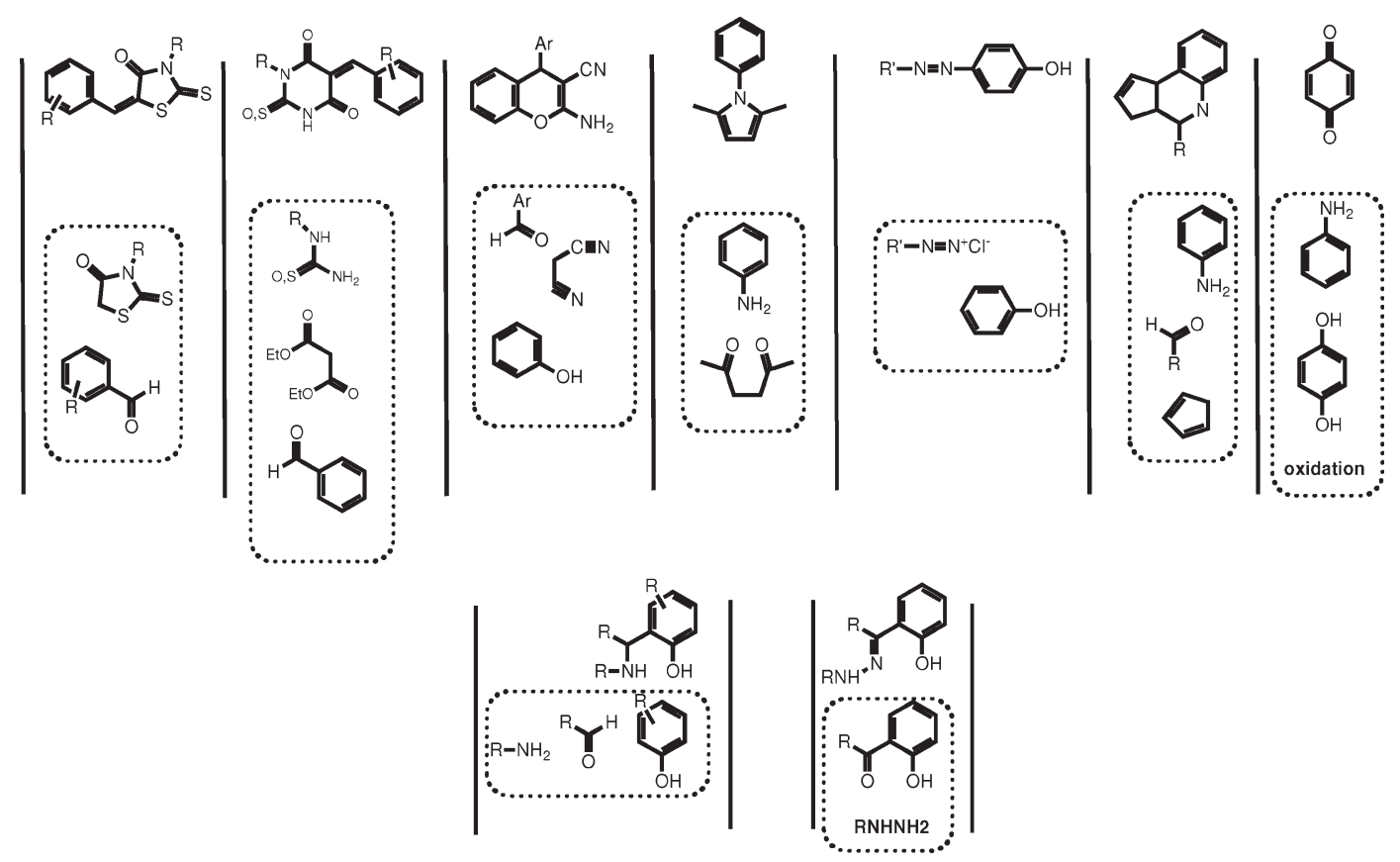

Figure 5. Many problematic screening compounds are constructed using facile chemistry.

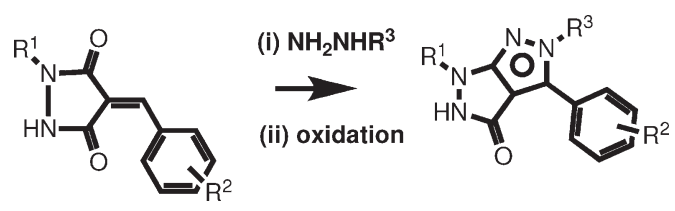

Figure 6. Putative synthetic route as an example how vendors could in principle decrease reactivity in problematic screening compounds while simultaneously introducing a diversity expansion through on-reaction with a suitable nucleophile.

Vendors might consider the feasibility of undertaking related tasks to furnish a new generation of diverse and less reactive screening compounds from compounds already in stock.

The Mechanisms of Action of PAINS. It is clear that some of the compound classes we describe that are associated with color, such as azo, quinones, and rhodanines, could interfere photometrically in our assays and could interfere in some other assay technologies where absorption of light in the range $570-620 \mathrm{~nm}$ would interfere in signaling. Interference in this fundamental way is recognized by invariance in the effective $\mathrm{IC}_{50}$ values returned. However, because no single class under study here exclusively hits all six assays under investigation, other mechanisms of assay interference must also be involved. While it is not clear for some PAINS, such as the fused tetrahydroquinolines, what the relevant mechanisms of assay interference may be, the structures of many compounds are suggestive of potential reactivity, in particular, through the bearing of an alkene activated toward nucleophilic attack. We provide literature evidence of this in many cases, and we conclude that protein reactivity is the plausible dominant mechanism for pan assay interference compounds. When we established our HTS library in 2003, there were no guidelines for exclusion of many of the compound classes we specifically discuss herein. Nevertheless, one might ask why we did not recognize such compounds as potentially reactive. The answer is that, to the uninitiated, it is not clear that they would be reactive to the extent that they would interfere routinely in our assays.
This is largely attributable to the cyclic, heterocyclic nature of many of these compounds such as the rhodanines, where the carbonyl is flanked by a heteroatom and the $\alpha$ carbon of the $\alpha, \beta$ unsaturated system is part of a ring. It appears that for many medicinal and bioorganic chemists, the effect is to "soften" the look of the resulting compound so as to disguise potential reactivity, unlike the case for standard linear $\alpha, \beta$ unsaturated ketones such as chalcones where the potential for reactivity is widely and readily recognized. In actual fact, the resulting 1,3-synplanar relationship between the carbonyl and alkene in these cyclic heterocycles may greatly facilitate reactivity through transition-state stabilization with an incoming nucleophile as has been observed with alkylidene condensates of Meldrum's acids. ${ }^{177}$ That reactivity is not extreme is clear by the observation that these compounds may selectively react with some proteins and not with others so that they do not register as a hit in every assay. This makes PAINS particularly insidious, as they might present as reasonable points for drug development in any given individual study and pass counter screen selectivity criteria that would remove false positives that intefere photometrically or some other direct way with assay signaling. Azo compounds, quinones, and catechols are groups that we deliberately included in our screening library and yet are groups that are sometimes strongly recommended as unsuitable to have in screening libraries. ${ }^{9-11,16}$ However, this recommendation is from the point of view of toxicity and poor development potential. The cancer focus in much of our Institute led us to include quinones, which are common in anticancer drugs as DNA-active cytotoxics. We saw the azo linkage, like the hydrazone linkage for example, as being potentially useful in linking two different binding elements to furnish a hit that otherwise may not be discovered. This has been a particularly successful philosophy, and our most successful program started with a hydrazone-containing screening hit. We had no reason to believe that quinones and azo compounds would interfere with our assays. However, we show here that they clearly do, and such compounds, 


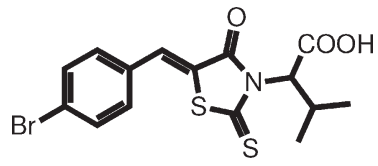

BH3l-1

Figure 7. Example of a rhodanine-based compound reported to induce apoptosis via binding to the Bcl-2 family of proteins, but it is probably nonspecific. $^{180}$

including catechols for the same reasons, are now filtered out before purchase for screening.

In addition to removing 2-aminothiazoles on the basis of light reactivity, contamination by reactive precursors (bromomethylketones) has also been a reason to spur some pharmaceutical companies into purging this entire class from screening libraries (Graeme Stevenson, personal communication). It is possible that some of our classes encode for the presence of reactive contaminant precursors such as those in Figure 5. However, we have not yet discovered any evidence of this when subjecting screening hits to LC/MS quality analysis. It is certainly the case that some PAINS may not be that stable, for example 3 (WEHI-60846) in Figure 2. Such pyrroles have been found by GlaxoSmithKline to be potentially unstable to hydrolysis during long-term storage in DMSO (Phil Sidebottom, personal communication). In this particular case, this compound registered an $\mathrm{IC}_{50}$ of $11-17 \mu \mathrm{M}(n=3)$ in a particular assay of interest (HTS campaign D in SI Table S2), was confirmed in a secondary (fluorescence polarization) assay, and was inactive in a control counter assay. The purity of this batch was satisfactory, although only just $(70 \%$ by LC/MS), and the solution was dark. However, no other major impurity was observed. A freshly purchased batch was analyzed at $80 \%$ purity, gave rise to a paler solution, and lost all activity. As a precursor, 2,5hexanedione was tested and found to be inactive, a finding in line with the relatively low protein nucleophile reactivity of aldehydes and ketones under typical screening conditions. ${ }^{157}$ The origin of the initial biological activity for this class of compounds remains a mystery. Even if some classes of PAINS do interfere through the presence of trace amounts of reactive contaminants, the structures represented in a vendor catalogue, and those identified by us, are still relevant as these are basis on which the compounds are sold.

Rhodanines comprise the most widely reported PAINS that we know of, due most likely to the ready availability and multiple pathways for reactivity. They are often also highly colored. Their promiscuity has been noted ${ }^{40}$ and their reactivity been subtly alerted to, either directly ${ }^{39}$ or indirectly. ${ }^{7}$ It has been suggested by Bristol-Myers Squibb that selective protein reactivity may be due in part to strain induced by initial, genuine, noncovalent affinity. ${ }^{39}$ Observation of light-induced reactivity further complicates the situation. ${ }^{38,39}$ With all these behaviors, biological readouts from rhodanine-based studies must inherently be uninterpretable. Despite this, there does not appear to be a general awareness of the critical limitations that these compounds have as development starting points. This is because, in isolation, the data furnished through study of these compounds can be convincing and it is not necessarily a fault of an author for submitting such data for publication nor that of a journal in accepting such work. However, this can lead others to undertake extensive and wasteful studies such as full efficacy, pharmacokinetic, tissue distribution, and metabolism studies destined for failure. ${ }^{178}$
We would also argue that PAINS are not useful as biochemical probes. The insidious nature of PAINS in this context is exemplified in BH3I-1 in Figure 7, a rhodaninebased compound that has been reported to induce apoptosis by binding to the Bcl-2 family of proteins. Extensive and meticulous data has been provided that gives credence to this hypothesis, and the work has justifiably been published in a high profile journal. ${ }^{179}$ Our Institute was in the fortunate position of having access to a Bax/Bak knockout cell line that was insensitive to compounds acting via the Bcl-2 family and so could be used to test whether this pathway was responsible for a given observed cytotoxic response. BH3I-1 was thus sourced and tested and was found to be equally cytotoxic to normal cells and Bax/Bak knockout cells. ${ }^{180}$ That is, its cytotoxicity was due to an interaction not involving the Bcl-2 family pathway as supposed and published. Rather, the ability of the rhodanine core to react with many proteins likely gave rise to cytotoxicity through interaction with one or more other unidentified cellular proteins important for cell viability.

Strikingly, in a series of recent papers from the Abbott Laboratories that describes a new method (ALARM NMR) for detecting protein-reactive problematic screening compounds, several identified compound classes match precisely those reported by us herein. These include rhodanines, catechols, quinones, benzofurazans, benzthioxalones, 2-amino-3-carbonylthiophenes, and certain dihydropyridines. ${ }^{6,7,157}$ Protein reactivity can arise via oxidation as well as electrophilic attack. Bristol-Myers Squibb have also identified rhodanines as frequent hitters. ${ }^{181}$ These findings were not available when we constructed our screening library, but even if they were, we would not have altered the selection criteria for used for the establishment of our WEHI 93K HTS library. This is because we would not have been certain how ALARM NMR-positive compounds, for example, would translate to assay interference in the context of our laboratories. However, we have shown here that several classes of ALARM NMR-positive compounds do indeed interfere in assays in our laboratories, and this is highly likely to be due to protein reactivity.

It is intriguing that the structures of a number of aggregate-forming compounds coincide with some of the PAINS that we discuss herein. ${ }^{2}$ This is despite the fact that our assays are run under high detergent conditions designed to halt aggregate formation. It is possible that either some PAINS form highly robust, detergent-resistant aggregates or that reactivity is a factor in some of Shoichet's frequent hitter aggregators. This remains to be investigated.

In summary, PAINS may interfere in biological assays in a number of ways. It seems likely that in many cases this could be due to protein reactivity, sometimes light induced, or due simply to interference in the photometric readout. For the latter, a simple spectroscopic analysis will provide an answer. For the former, it appears that Abbott's ALARM NMR assay may currently be the best validated method, although it is unclear how readily this assay could be established in academic laboratories. In many cases, it remains unknown how a given class of PAINS may be interfering in biological assays and several mechanisms may be possible within each class. Further investigation may lead to answers that could also provide a rationale to establish robust and cheap diagnostic methods to assess for PAINS, and this would be a highly useful endeavor. This could be accomplished, for example, by studying analogue clusters around each of the 480 assay interference substructures defined in SI 


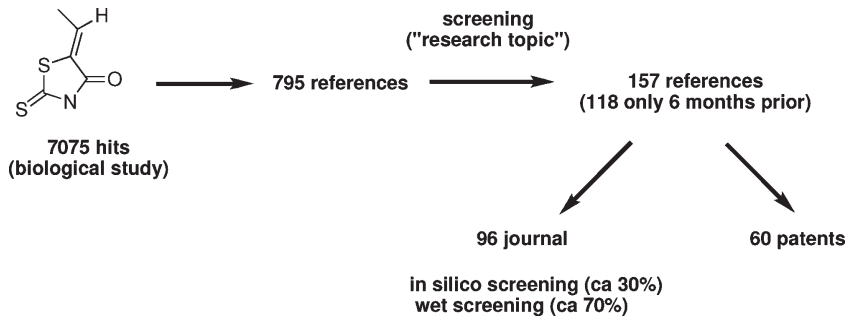

Figure 8. A literature searching exercise that illustrates the significant number of screening-based publications and patents involving rhodanines.

Tables S6-S8, and we would encourage any researchers who are interested in doing so. This would also be useful for those cases in SI Table S8, where few analogues are represented and so little can currently be said about the detail of the substructure responsible for assay interference or the mechanism involved. We note two useful recent additions to the literature on nuisance compound detection by GlaxoSmithKline for redox-active assay interference compounds that can oxidize thiols. ${ }^{182,183}$ Time-dependent activity or unusual Hill coefficients can usefully point to general assay interference/protein-reactive compounds ..$^{92,184,185}$

Increasing Prevalence of PAINS in the Screening Literature. A simple literature searching exercise reveals the influence that rhodanine-based PAINS are having on the scientific literature. As shown in Figure 8, there are 7075 rhodanine analogues associated with a published biological study and this translates to 795 references. When filtered using the research topic "screening", 157 references $(20 \%)$ are retained. The same exercise repeated for 2-aminopyridines returns only $4.5 \%$ of references. Rather than being privileged structures, we suggest rhodanines are polluting the scientific literature and this exercise undertaken some six months prior returned only 118 references.

These screening references comprise 96 journal articles, with approximately $70 \%$ being wet screening-based publications and $30 \%$ being in silico screening-based publications. The latter represent in silico-derived hits that have then been tested in vitro. In other words, in silico screening will return protein-reactive compounds as positives in just the same way that wet screening will and it is through such PAINS that the data may ironically become more publishable. This is not so surprising but is unfortunate because subsequent in silico publications commonly cite previous ones as examples of successful in silico screening methodology. Rather than representing a privileged structure, we conclude here that these results reflect the extent of wasted resources that these nuisance compounds are generally causing. We suggest that a significant proportion of screening-based publications and patents may contain assay interference hits and that extensive docking computations and graphics that are frequently produced may often be meaningless. In the case of rhodanines, the answer set represents some 60 patents and we have found patents to be conspicuously prevalent for other classes of PAINS. This collectively represents an enormous cost in protecting intellectual property, much of which may be of little value. Extreme examples can occur where assays involve targets with multiple catalytic cysteines and thus tend to select for reactive compounds. For example, PAINS appear to dominate the set of all known inhibitors of a number of E3 ligases. ${ }^{186}$

We are concerned with this trend and so have specifically disclosed in the work presented herein what we consider to be the worst offending PAINS. Together with the studies by Abbott $^{6,7,157}$ and Bristol-Myers Squibb ${ }^{181}$ and backed up by our literature investigation, we propose the evidence is sufficient to indict our suggested PAINS as genuinely problematic compounds and poor choices for drug development. For the purposes of maximizing chemical diversity for any possible use, we would be hesitant to suggest that compound vendors may consider purging their databases of these compounds. However, we would suggest they be issued with an alert as being poorly suited for drug development and highly likely to register as screening hits.

Drugs Containing PAIN Substructures. The Shoichet group has shown that promiscuous aggregating inhibitors can count many drugs among their numbers. ${ }^{187}$ Likewise, it cannot be categorically ruled out that compounds with substructures that we classify as PAINS may still in theory be viable points for development. For example, Serono appears to be developing some rhodanine-like compounds as PI3K $\gamma$ inhibitors. ${ }^{188,189}$ Their lead compound appears to be highly selective, with reasonable pharmacokinetic parameters, and forms a noncovalent crystal structure complex. Unstable benzofurazans have also formed the basis for successful early hit-to-lead optimization. ${ }^{145}$ It is also true that some marketed drugs contain PAIN structures, and these are given in SI Figure S2. However, not only are these percentages relatively small $(2.8-6.5 \%$ as shown in Table 7$)$ but the substructures recognized by our filters appear to be strikingly linked with metabolic or toxicity-associated deficiencies, ${ }^{7,190-203}$ with few exceptions. ${ }^{204}$ We provide an extended discussion on this in the SI.

We note that in the areas of oncology, microbiology, and parasitology, reactive, photosensitive, and redox-active compounds (many of which are dyes) may be particularly suited for therapeutic uses. Methylene blue, for example, is a redox-active phenothiazine dye that was discovered by Guttmann and Ehrlich more than 100 years ago to have useful antimalarial activity and so constituted the very first chemotherapeutic. ${ }^{205}$ Trypan blue and trypan red are azo dyes synthesized and discovered in 1904 (also by Ehrlich) to have potent trypanocidal activity (hence the name given to the dyes). ${ }^{206}$ We have also found novel assay interference dyes with potent antiparasitic activity, ${ }^{15}$ and interest in antiparasitic dyes continues strongly to this day. ${ }^{207-210}$ Many of these compounds will be removed by our filters, and so workers in these areas may usefully work with focused libraries containing such compounds that are otherwise unacceptable for general screening. ${ }^{211}$

In summary, application of our filters will remove some compounds that in principle could be acceptable as marketed drugs. However, in general, the moieties that our filters recognize are also those often associated with drug toxicity and reactivity or metabolic liability. This point has also been made by Abbott, and known drugs that are active in their ALARM-NMR protein-reactivity assay tend to have associated limitations in therapeutic settings. ${ }^{7}$ These represent a suboptimum starting point for development, and we are comfortable with the exclusion of compounds bearing assay interference moieties from our screening libraries. However, by far the most important point to make is that, in general, any compound recognized by our filters that arises from a screen is likely to be a false positive or problematic and not yield to conventional SAR and optimization. The nuisance value of these therefore far outweighs the small chance that the particular hit will yield to optimization. 
Publication Policies for Screening-Based Manuscripts. We are making the structures of PAINS available on several levels: first, as precisely encoded Sybyl line notation files that others may copy as text files and use directly on screening hitlists (SI Tables S6-S8) using Sybyl; second, as less precise but more visual 2D structures that are grouped according to broad compound classes (SI Figure S1). Our PAIN-recognition filters should be used in conjunction with the prior functional groups filters, which we also provide (SI Table $\mathrm{S} 1$ ). For example, a given nitroalkene may be problematic but not recognized by our PAIN filters because nitro groups were filtered out prior to library construction. Similarly, benzyl bromides would be likely PAINS but would also be filtered out prior and it is disappointing that such clearly highly reactive compounds continue to make it into the screening-based literature. ${ }^{74}$

For those workers with screening hits that are recognized by our filters (or with hits clearly related but maybe falling outside the strict definition we provide), this should serve as a signal to thoroughly investigate those compounds for potential assay interference mechanisms and elucidation of early SAR. This is relevant to any compound tested in a biological assay, whether its origin may lie in wet screening, in silico screening, or rational design.

Where these hits correspond to the worst offenders that we have identified as PAINS, we suggest that an alert should be issued with any pending publication. To editors and reviewers, manuscripts describing PAIN-bearing structures as optimizable screening hits should be viewed with extreme caution, should be backed up by extensive SAR and biophysical characterization, and should be accompanied by comparisons with literature SAR. An SAR set of only a few compounds is an insufficient demonstration of SAR, as a small selection set can exhibit apparent SAR that dissipates on expansion. A special alert should be issued when different classes of PAINS are coreported in the one screening-based manuscript. Proof of mechanism-of-action should accompany any target-based screening hit with associated cell-based activity in order to gain credibility as a valid probe or developable compound. There is the case to argue for the establishment of a facility that can perform interference assays similar to those already published ${ }^{4-8,101,157,182,183}$ and to which researchers can submit their confirmed hits. This would not be out of place as part of the NIH Molecular Libraries Initiative (see ref 213).

As an editorial board member for Future Medicinal Chemistry, one of us (J.B.B.) is working to introduce such measures for that journal. A lack of literature SAR should not necessarily be viewed favorably, as it may simply be that a given PAIN may represent relatively uncommon chemistry and has yet to build a body of relevant literature. The numbers of compounds in our WEHI 93K HTS library that belong to each class of problematic compounds, as provided in SI Figure S1 and SI Table S9, can be used as a guide to assess how common such compounds have been and may still be in vendor databases.

\section{Conclusions}

We have identified problematic screening compounds and constructed substructure filters that recognized these compounds. We have shown that these interference compounds are not unique to our library but are also prevalent in a primary hit set derived from an independent screening library. These compounds remain common in vendor cata- logues. We have been able to implement these filters in the establishment of a new 136K-strong HTS compound library, and early results indicate that cleaner sets of primary screening hits result. This will save significant up-front and recurring costs as well as making hit set analysis and interpretation easier. $^{212}$ We have provided our filters so that they may be of use to others similarly. The substructural filters presented here were identified from the results of a number of proteinprotein interaction screens using the AlphaScreen technology. However, these filters also appear to identify compounds which have been cited in the literature as being active in a number of different assays using differing detection technologies. Hence, our filters do not encode for compounds peculiar only to our assay technology or our targets or our HTS library. We discuss that this is likely due to the ability of certain compound classes to interfere in screening technologies via a number of means but particularly through protein reactivity so that essentially any bioassay may be affected. We have termed these compounds PAINS (pan assay interference compounds) as they represent poor choices for $\overline{\mathrm{d}} \mathrm{rug}$ development and yet can furnish data that in isolation may be suggestive of a selective and optimizable hit. These characteristics have led to a rapidly growing body of potentially misleading literature. In a series of seminal recent papers, researchers at Abbott Laboratories have published on unexpected protein reactivity in some screening compounds. ${ }^{6,7,157}$ At the time it was not widely appreciated how significant a problem this may generally be, nor still is this widely appreciated, at least among the newer generation of HTS academics. A number of classes identified by workers at Abbott coincide precisely with those identified by us, and we now suggest that all researchers in hit discovery should be made more overtly aware that these compounds are readily available and will be prevalent as convincing screening hits but acting via protein reactivity (potentially light-induced) as well as other possible mechanisms as yet undefined. We suggest that literature describing their biological relevance should be viewed very cautiously.

It has recently been shown that in the absence of detergent, aggregators can dominate the set of primary hits and that reactive compounds are relatively less problematic. ${ }^{213} \mathrm{We}$ do not disagree with this. However, through the use of assays run under "high detergent" conditions ${ }^{213}$ (see SI Table S2), we have been able to focus on the remaining hits and have been able to define certain compound classes that are highly problematic in the sense that they are prone to assay interference yet may escape extensive reactive functional group filters that have been developed for these purposes. ${ }^{213}$

In recognition of the increasing use of HTS facilities by academic researchers, guidelines have recently been proposed to strengthen the link between screening data and compound structural integrity. ${ }^{214}$ We heartily endorse these guidelines, but we wish to alert hit discovery researchers that even if compound integrity is confirmed, for certain compound classes (PAINS, as we describe herein), great caution must be exercised in interpreting biological results. A discussion on structural integrity for a particular screening hit, mirin, has ensued recently in the literature, along with the publication of a corrected structure. ${ }^{215}$ Somewhat ironically, we would strongly identify the corrected structure as a rhodanine-based PAIN and prone to give misleading biological results.

Finally, we note that the 50 millionth chemical substance was recorded recently by CAS scientists, to some fanfare. ${ }^{216}$ This compound is one of some 230 compounds claimed in a 199 page patent as potential medicaments for neuropathic 
pain. ${ }^{217}$ Every one is an alkylidenethiazolone of the type strongly identified by us as an assay interference core with potential protein reactivity due to the reactive $\alpha, \beta$-unsaturated carbonyl group and likely to represent a "false start".

We have in the past incurred substantial resource costs in following up such compounds and others depicted in Figures 2 and 4, which we now recognize and which our substructure filters recognize as PAINS. Here, we have fully disclosed our substructure filters for others to utilize in the hope that awareness is raised about these problematic compounds.

\section{Experimental Section}

Construction of substructure filters involved an iterative process involving use of Tripos Software (Syby18.0) for defining substructures and interrogation of our HTS data using the LIM system ActivityBase (idbs) to retrieve the assay hit counts for every compound recognized by that filter. Filtering out compounds from any given sd file using our filters simply requires the following commands on a Linux operating platform (assuming an sd file of name file1.sdf with the id field being "Object_ID"). The output is a list of the compounds recognized by our filters as being problematic (PAINS.txt) and compounds not recognized by our filters as being problematic (CLEAN.txt). The processing includes stripping all compounds of salts, neutralizing, and "uniqueing" the sin so that duplicates can be identified.

dbtranslate -type maccs -translate sln -input filel.sdf -output output.hits -maccs_regname Object_ID -property_data + unique $-2 \mathrm{~d}$

sleep 1

dbstripsalt -omitted salts_all.hits + neutralize -output output_ neutral.hits $<$ output.hits

sleep 1

dbslnfilter -type sln -input output_neutral.hits -badgroups Freq_Hit_5_morethan150.hits -omitted outputA.hitters -hitlist outputA.hits

sleep 1

dbslnfilter -type sln -input outputA.hits -badgroups Freq_Hit_5_ lessthan150.hits -omitted outputB.hitters -hitlist outputB.hits dbslnfilter -type $\sin$-input outputB.hits -badgroups Freq_Hit_ 5 lessthan15.hits -omitted outputC.hitters -hitlist outputC. hits

sleep 1

cat outputA.hitters outputB.hitters $>$ filel

cat file1 outputC.hitters > output_final.hitters

cat outputA.hits outputB.hits $>$ file 2

cat file2 outputC.hits $>$ output_final.hits

dbhitlist -convert regkeys -output PAINS.txt output_final. hitters

dbhitlist -convert regkeys -output CLEAN.txt output_final.hits

Acknowledgment. This analysis would not have been possible without the effort of the WEHI HTS group in conducting the many HTS campaigns that have been run over the last six years. We acknowledge here in particular Ian Street, John Parisot, Kurt Lackovic, Rebecca Moss, John Manzi, Katrina Billington, Theresa Connor, Patricia Novello, Hong Yang, and Effie Hatzis. For useful discussions on frequent hitters, we acknowledge Keith Watson, Guillaume Lessene, Graeme Stevenson, Ian Holmes, Andrew Holmes, and Leon Wong, Carl Rye, Brad Sleebs, Simon Campbell, and Phil Sidebottom. We further thank Ian Holmes, David Manallack, Greg Fechner, and Maureen Beresini for the provision of some compound electronic files used in this paper. We acknowledge the financial support of the Cancer Therapeutics CRC, established and supported under the Australian Government's Cooperative Research Centres Program. Last, we thank the NHMRC for funding support (NHMRC
IRIISS grant no. 361646) and the Victorian State Government for funding support (OIS Grant).

Supporting Information Available: Supporting tables and figures as described in the text, including our PAINS filters in Sybyl line notation. This material is available free of charge via the Internet at http://pubs.acs.org.

\section{References and Notes}

(1) Diller, D. J.; Hobbs, D. W. Deriving knowledge through data mining high-throughput screening data. J. Med. Chem. 2004, 47, 6373-6383.

(2) McGovern, S. L.; Caselli, E.; Grigorieff, N.; Shoichet, B. K. A common mechanism underlying promiscuous inhibitors from virtual and high-throughput screening. J. Med. Chem. 2002, 45, 1712-1722.

(3) McGovern, S. L.; Shoichet, B. K. Kinase inhibitors: not just for kinases anymore. $J$. Med. Chem. 2003, 46, 1478-1483.

(4) Feng, B. Y.; Shelat, A.; Doman, T. N.; Guy, R. K.; Shoichet, B. K. High-throughput assays for promiscuous inhibitors. Nat. Chem. Biol. 2005, 1, 146-148.

(5) Feng, B. Y.; Shoichet, B. K. Synergy and antagonism of promiscuous inhibition in multiple-compound libraries. J. Med. Chem. 2006, 49, 2151-2154.

(6) Metz, J. T.; Huth, J. R.; Hajduk, P. J. Enhancement of chemical rules for predicting compound reactivity towards protein thiol groups. J. Comput.-Aided. Mol. Des. 2007, 21, 139-144.

(7) Huth, J. R.; Song, D.; Mendoza, R. R.; Black-Schaefer, C. L.; Mack, J. C.; Dorwin, S. A.; Ladror, U. S.; Severin, J. M.; Walter, K. A.; Bartley, D. M.; Hajduk, P. Toxicological evaluation of thiol-reactive compounds identified using a La assay to detect reactive molecules by nuclear magnetic resonance. Chem. Res. Toxicol. 2007, 20, 1752-1759.

(8) Ryan, A. L.; Gray, N. M.; Lowe, P. N.; Chung, C. Effect of detergent on promiscuous inhibitors. J. Med. Chem. 2003, 46, 3448-3451.

(9) Rishton, G. M. Reactive compounds and in vitro false positives in HTS. Drug Discovery Today 1997, 2, 382-384.

(10) Hann, M.; Hudson, B.; Lewell, X.; Lifely, R.; Miller, L.; Ramsden, N. Strategic pooling of compounds for high-throughput screening. J. Chem. Inf. Comput. Sci. 1999, 39, 897-902.

(11) Walters, W. P.; Murcko, M. A. Prediction of "drug-likeness". Adv. Drug Delivery Rev. 2002, 54, 255-271.

(12) Hann, M. M.; Leach, A. R.; Harper, G. Molecular complexity and its impact on the probability of finding leads for drug discovery. J. Chem. Inf. Comput. Sci. 2001, 41, 856-864.

(13) Oprea, T. I.; Davis, A. M.; Teague, S. J.; Leeson, P. D. Is there a difference between leads and drugs? A historical perspective. J. Chem. Inf. Comput. Sci. 2001, 41, 1308-1315.

(14) Holloway, G. A.; Baell, J. B.; Fairlamb, A. H.; Novello, P. M.; Parisot, J. P.; Richardson, J.; Watson, K. G.; Street, I. P. Discovery of 2-iminobenzimidazoles as a new class of trypanothione reductase inhibitor by high throughput screening. Bioorg. Med. Chem. Lett. 2007, 17, 1422-1427.

(15) Holloway, G. A . Charman, W. N.; Fairlamb, A. H. Brun, R; Kaiser, M; Kostewicz, E; Novello, P. M.; Parisot, J. P.; Richardson, J; Street, I. P.; Watson, K. G.; Baell, J. B. Trypanothione reductase high-throughput screening campaign identifies novel classes of inhibitors with anti-parasitic activity. Antimicrob. Agents Chemother. 2009, 53, 2824-2833.

(16) Verheij, H. J. Leadlikeness and structural diversity of synthetic screening libraries. Mol. Diversity 2006, 10,377-388.

(17) Zhang, J.-H.; Chung, T. D. Y.; Oldenburg, K. R. A simple statistical parameter for use in evaluation and validation of high throughput screening assays. J. Biomol. Screening 1999, 4, $67-73$.

(18) Gould, D. M.; Spiro, M.; Griffith, W. P. Mechanism of bleaching by peroxides. Part 6 . Kinetics of the peroxide bleaching of methyl orange catalysed by $\mathrm{MoO}_{4}{ }^{2-}$ and $\mathrm{WO}_{4}{ }^{2-}$ at $\mathrm{pH}$ 10. J. Mol. Catal. A: Chem. 2005, 234, 145-150.

(19) Miyajima, K.; Komatsu, H.; Inoue, K.; Handa, T.; Nakagari, M. The protective effects of cyclodextrins against the oxidation of methyl orange by singlet oxygen. Bull. Chem. Soc. Jpn. 1990, 63, 6-10.

(20) It is also possible that this represents a concerted effort by compound vendors from 2003 to 2007 to remove fluorescence interference compounds from their screening libraries.

(21) Schepetkin, I. A.; Khlebnikov, A. I.; Kirpotina, L. N.; Quinn, M. T. Novel small-molecule inhibitors of anthrax lethal factor identified by high-throughput screeing. J. Med. Chem. 2006, 49, $5232-5244$ 
(22) Forino, M.; Johnson, S.; Wong, T. Y.; Rozanov, D. V.; Savinov, A. Y.; Li, W.; Fattorusso, R.; Becattini, B.; Orry, A. J.; Jung, D.; Abagyan, R. A.; Smith, J. W.; Alibek, K.; Liddington, R. C.; Strongin, A. Y.; Pellechia, M. Efficient synthetic inhibitors of anthrax lethal factor. Proc. Natl Acad. Sci. U.S.A. 2005, 102, 9499-9504.

(23) Hu, Y.; Helm, J. S.; Chen, L.; Ginsberg, C.; Gross, B.; Kraybill, B.; Tiyanont, K.; Fang, X.; Wu, T.; Walker, S. Identification of selective inhibitors for the glycosyltranserase MurG via highthroughput screening. Chem. Biol. 2004, 11, 703-711.

(24) Severson, W. E.; Shindo, N.; Sosa, M.; Fletcher, T., III; White, E. L.; Ananthan, S.; Jonsson, C. B. Development and validation of a high-throughput screen for inhibitors of SARS CoV and its application in screening of a 100000-compound library. J. Biomol. Screening 2007, 12, 33-40.

(25) Park, H.; Jung, S.-K.; Jeong, D. G.; Ryu, S. E.; Kim, S. J. Discovery of novel PRL-3 inhibitors based on the structure-based virtual screening. Bioorg. Med. Chem. Lett. 2008, 18, 2250-2255.

(26) Kim, H. J.; Choo, H.; Cho, Y. S.; No, K. T.; Pae, A. N. Novel GSK-3 $\beta$ inhibitors from sequential virtual screening. Bioorg. Med. Chem. Lett. 2008, 16, 636-643.

(27) Polgar, T.; Baki, A.; Szendrei, G. I.; Keseru, G. M. Comparative virtual and experimental high-throughput screening for glycogen synthase kinase- $3 \beta$ inhibitors. J. Med. Chem. 2005, 48, 79467959.

(28) Dayam, R.; Al-Mawsawi, L. Q.; Zawahir, Z.; Witvrouw, M.; Debyser, Z.; Neamati, N. Quinolone 3-carboxylic acid pharmacophore: design of second generation HIV-1 integrase inhibitors. J. Med. Chem. 2008, 51, 1136-1144.

(29) Rajamaki, S.; Innitzer, A.; Falciani, C.; Tintori, C.; Christ, F.; Witvrouw, M.; Debyser, Z.; Massa, S.; Botta, M. Exploration of novel thiobarbituric acid-, rhodanine- and thiohydantoin-based HIV-1 integrase inhibitors. Bioorg. Med. Chem. Lett. 2009, 19, 3615-3618.

(30) Park, H; Bahn, Y. J.; Jeong, D. G.; Woo, E. J.; Kwon, J. S.; Ryu, $\mathrm{S}$. E. Identification of novel inhibitors of extracellular signalregulated kinase 2 based on the structure-based virtual screening. Bioorg. Med. Chem. Lett. 2008, 18, 7372-5376.

(31) Bulic, B.; Pickhardt, M.; Khlistunova, I.; Biernat, J.; Mandelkow, E.-M.; Mandelkow, E.; Waldmann, H. Rhodanine-based tau aggregation inhibitors in cell models of tauopathy. Angew. Chem., Int. Ed. 2007, 46, 9215-9219.

(32) Johnson, S. L.; Chen, L.-H.; Harbach, R.; Sabet, M.; Savinov, A.; Cotton, N. J. H.; Strongin, A.; Guiney, D.; Pellecchia, M. Rhodanine derivatives as selective protease inhibitors against bacterial toxins. Chem. Biol. Drug Des. 2008, 71, 131-139.

(33) Kumar, G.; Parasuraman, P.; Sharma, S. K.; Banerjee, T.; Karmodiya, K.; Surolia, N.; Surolia, A. Discovery of a rhodanine class of compounds as inhibitors of Plasmodium falciparum enoylacyl carrier protein reductase. J. Med. Chem. 2007, 50, 2665-2675.

(34) Bjorkland, M.; Aitio, O.; Stefanidakis, M.; Suojanen, J.; Salo, T.; Sorsa, T.; Koivunen, E. Stabilization of activated $\alpha_{M} \beta_{2}$ integrin by a small molecule inhibits leukocyte migration and recruitment. Biochemistry 2006, 45, 2862-2871.

(35) Kim, J.; Lee, M.; Kim, Y.-Z. Purification and characterization of HCV RNA-dependent RNA polymerase from Korean genotype $1 \mathrm{~b}$ isolate: implications for discovery of HCV polymerase inhibitors. Bull. Korean Chem. Soc. 2005, 26, 285-291.

(36) Powers, J. P.; Piper, D. E; Li, Y.; Mayorga, V.; Anzola, J.; Chen, J. M.; Jaen, J. C.; Lee, G.; Liu, J.; Peterson, M. G.; Tonn, G. R.; Ye, Q.; Walker, N. P. C.; Wang, Z. SAR and mode of action of novel non-nucleoside inhibitors of hepatitis C NS5b RNA polymerase. J. Med. Chem. 2006, 49, 1034-1046.

(37) Lee, G.; Piper, D. E.; Wang, Z.; Anzola, J.; Powers, J.; Walker, N.; $\mathrm{Li}, \mathrm{Y}$. Novel inhibitors of hepatitis C virus RNA-dependent RNA polymerase. J. Mol. Biol. 2006, 357, 1051-1057.

(38) Carter, P. H.; Scherle, P. A.; Muckelbauer, J. A.; Voss, M. E.; Liu, R.-Q.; Thompson, L. A.; Tebben, A. J.; Solomon, K. A.; Lo, Y. C.; Li, Z.; Strzemienski, P.; Yang, G.; Falahatpisheh, N.; Xu, M.; Wu, Z.; Farrow, N. A.; Ramnarayan, K.; Wang, J.; Rideout, D.; Yalamoori, V.; Domaille, P.; Underwood, D. J.; Trzaskos, J. M.; Friedman, S. M.; Newton, R. C.; Decicco, C. P. Photochemically enhanced binding of small molecules to the tumor necrosis factor receptor-1 inhibits the binding of TNF- $\alpha$. Proc. Natl. Acad. Sci. U.S.A. 2001, 98, 11879-11884

(39) Voss, M. E.; Carter, P. H.; Tebben, A. J.; Scherle, P. A.; Brown, G. D.; Thompson, L. A.; Xu, M.; Lo, Y. C.; Yang, G.; Liu, R.-Q.; Strzemienski, P.; Everlof, J. G.; Trzaskos, J. M.; Decicco, C. P. Both 5-arylidene-2-thioxodihydropyrimidine-4,6(1H,5H)-diones and 3-thioxo-2,3-dihydro- $1 H$-imidazo[1,5- $a]$ indol-1-ones are light-dependent tumor necrosis factor- $\alpha$ antagonists. Bioorg. Med. Chem. Lett. 2003, 13, 533-538.
(40) Carlson, E. E.; May, J. F.; Kiessling, L. L. Chemical probes of UDP-galactopyranose mutase. Chem. Biol. 2006, 13, 825-837.

(41) Huang, N.; Nagarsekar, A.; Xia, G.; Hayashi, J.; MacKerell, A. D., Jr. Identification of non-phosphate-containing small molecular weight inhibitors of the tyrosine kinase p56 Lck SH2 domain via in silico screening against the $\mathrm{pY}+3$ binding site. J. Med. Chem. 2004, 47, 3502-3511.

(42) Park, H.; Jung, S.-K.; Jeong, D. G.; Ryu, S. E.; Kim, S. J. Discovery of VHR phosphotase inhibitors with micromolar activity based on structure-based virtual screening. ChemMedChem 2008, 3, 877-880.

(43) Edwards, B. S.; Bologa, C.; Young, S. M.; Balakin, K. V.; Prossnitz, E. R.; Savchuck, N. P.; Sklar, L. A.; Oprea, T. I. Integration of virtual screening with high-throughput flow cytometry to identify novel small molecule formylpeptide receptor antagonists. Mol. Pharmacol. 2005, 68, 1301-1310.

(44) Andre, E.; Bastide, L.; Michaux-Charachon, S.; Gouby, A.; VillainGuillot, P.; Latouche, J.; Bouchet, A.; Gualtieri, M.; Leonetti, J.-P. Novel synthetic molecules targeting the bacterial RNA polymerase assembly. J. Antimicrob. Chemother. 2006, 57, 245-251.

(45) Pipalia, N. H.; Huang, A.; Ralph, H.; Rujoi, M.; Maxfield, F. R. Automated microscopy screening for compounds that partially revert cholesterol accumulation in Niemann-Pick C cells. J. Lipid Res. 2006, 47, 284-301.

(46) Howard, M. H.; Cenizal, T.; Gutteridge, S.; Hann, W. S.; Tao, Y.; Totrov, M.; Wittenbach, V. A.; Zhen, T.-j. A novel class of inhibitors of peptide deformylase discovered through highthroughput screening and virtual ligand screening. J. Med. Chem. 2004, 47, 6669-6672.

(47) Zawahir, Z.; Dayam, R.; Deng, J.; Pereira, C.; Neamati, N. Pharmacophore guided discovery of small-molecule human apurinic/apyrimidinic endonuclease 1 inhibitors. J. Med. Chem. 2009, 52, 20-32.

(48) Bursavich, M. G.; Gilbert, A. M.; Lombardi, S.; Georgiadis, K. E.; Reifenberg, E.; Flanery, C. R.; Morris, E. A. Synthesis and evaluation of aryl thioxothiazolidinone inhibitors of ADAMTS-5 (Aggrecanase-2). Bioorg. Med. Chem. Lett. 2007, $17,1185-1188$.

(49) Smith, T. K.; Young, B. L.; Denton, H.; Hughes, D. L.; Wagner, G. K. First small molecular inhibitors of T. brucei dolicholphosphate mannose synthase (DPMS), a validated drug target in African sleeping sickness. Bioorg. Med. Chem. Lett. 2009, 19, 1749-1752.

(50) Han, C.; Zhang, J.; Chen, L.; Kaixian, C.; Shen, X.; Jiang, H. Discovery of Helicobacter pylori shikimate kinase inhibitors: bioassay and molecular modelling. Bioorg. Med. Chem. 2007, $15,656-662$

(51) Doman, T. N.; McGovern, S. L.; Witherbee, B. J.; Kasten, T. P.; Kurumbail, R.; Stallings, W. C.; Connolly, D. T.; Shoichet, B. K. Molecular docking and high-throughput screening for novel inhibitors of protein tyrosine phosphatase-1B. J. Med. Chem. 2002, 45, 2213-2221.

(52) Tautz, L.; Bruckner, S.; Sareth, S.; Alonso, A.; Bogetz, J.; Bottini, N.; Pellecchia, M.; Mustelin, T. Inhibition of Yersinia tyrosine phosphatase by furanyl salicylate compounds. J. Biol. Chem. 2005, 280, 9400-9408.

(53) Stebbins, J. L.; Jung, D.; Leone, M.; Zhang, X.-k.; Pellechia, M. A structure-based approach to retinoid $\mathrm{x}$ receptor- $\alpha$ inhibition. J. Biol. Chem. 2006, 281, 16643-16648.

(54) Hu, X.; Prehna, G.; Stebbins, C. E. Targeting plague virulence factors: a combined machine learning method and multiple conformational virtual screening for the discovery of Yersinia protein kinase A inhibitors. J. Med. Chem. 2007, 50, 3980-3983.

(55) Mashhoon, N.; Pruss, C.; Carroll, M.; Johnson, P. H.; Reich, N. O. Selective inhibitors of bacterial DNA adenine methyltransferases. J. Biomol. Screening 2006, 11, 497-510.

(56) Vikramadithyan, R. K.; Chakrabarti, R.; Misra, P.; Premkumar, M.; Kumar, S. K. B.; Rao, C. S.; Ghosh, A.; Reddy, K. N.; Uma, C.; Rajagopalan, R. Euglycemic and hypolipidermic activity of PAT5A: a unique thiazolidinedione with weak peroxisome proliferator activated receptor gamma activity. Metabolism 2000, 49, 1417-1424.

(57) Misra, P.; Chakrabarti, R.; Vikramadithyan, R. K.; Bolusu, G.; Juluri, S.; Hiriyan, J.; Gershome, C.; Rajjak, A.; Kashreddy, P.; Yu, S.; Surapureddi, S.; Qi, C.; Zhu, Y.-J.; Rao, M. S.; Reddy, J. R.; Ramanugam, R. PAT5A: A partial agonist of peroxisome proliferator-activated receptor $\gamma$ is a potent antidiabetic thiazolidinedione yet weakly adipogenic. J. Pharmacol. Exp. Ther. 2003, 306, 763-771.

(58) Yang, J.; Wei, S.; Wang, D.-S.; Wang, Y.-C.; Kulp, S. K.; Chen, C.-S. Pharmacological exploitation of the peroxisome proliferatoractivated receptor $\gamma$ agonist ciglitazone to develop a novel class 
of androgen receptor-ablative agents. J. Med. Chem. 2008, 51, 2100-2107.

(59) Chittiboyina, A. G.; Venkatraman, M. S.; Mizuno, C. S.; Desai, P. V.; Patny, A.; Benson, S. C.; Ho, C. I.; Kurtz, T. W.; Pershadsingh, H. A.; Avery, M. A. Design and synthesis of the first generation of dithiolane thiazolidinedione- and phenylacetic acid-based PPAR $\gamma$ agonists. J. Med. Chem. 2006, 49, 4072-4084.

(60) Huang, J.-W.; Shiau, C.-W.; Yang, J.; Wang, D.-S.; Chiu, H.-C.; Chen, C.-Y.; Chen, C.-S. Development of small-molecule cyclin D1-ablative agents. J. Med. Chem. 2006, 49, 4684-4689.

(61) Maccari, R.; Ottana, R.; Curinga, C.; Vigorita, M. G.; Rakowitz, D.; Steindl, T.; Langer, T. Structure-activity relationships and molecular modelling of 5-arylidene-2,4-thiazolidinediones active as aldose reductase inhibitors. Bioorg. Med. Chem. 2005, 13, 2809-2823.

(62) Maccar, R.; Ottana, R.; Ciurleo, R.; Rakowitz, D.; Matuszczak, B.; Laggner, C.; Langer, T. Synthesis, induced-fit docking investigations, and in vitro aldose reducase inhibitory activity of noncarboxylic acid containing 2,4-thiazolidinedione derivatives. Bioorg. Med. Chem. 2008, 16, 5840-5852.

(63) Maccari, R.; Paoli, P.; Ottana, R.; Jacomelli, M.; Ciurleo, R.; Manao, G.; Steindl, T.; Langer, T.; Vigorita, M. G.; Camici, G. 5-Arylidene-2,4-thiazolidinediones as inhibitors of protein tyrosine phosphatases. Bioorg. Med. Chem. 2007, 15, 5137-5149.

(64) Xia, Z.; Knaak, C.; Ma, J.; Beharry, Z. M.; McInnes, C.; Wang, W.; Kraft, A. S.; Smith, C. D. Synthesis and evaluation of novel inhibitors of Pim-1 and Pim-2 protein kinases. J. Med. Chem. 2009, 52, 74-86.

(65) Ma, T.; Thiagarajah, J. R.; Yang, H.; Sonawane, N. D.; Folli, C.; Galietta, L. J. V.; Verkman, A. S. Thiazolidinone CFTR inhibitor identified by high-throughput screening blocks cholera toxininduced intestinal fluid secretion. J. Clin. Invest. 2002, 110, 1651-1658.

(66) Kim, N. D.; Yoon, J.; Kim, J. H.; Lee, J. T.; Chon, Y. S.; Hwang, M.-K.; Ha, I.; Song, W.-J. Putative therapeutic agents for the learning and memory deficits of people with Down syndrome. Bioorg. Med. Chem. Lett. 2006, 16, 3772-3776.

(67) Geronikaki, A. A.; Lagunin, A. A.; Hadjipavlou-Litina, D. I.; Eleftheriou, P. T.; Filimonov, D. A.; Poroikov, V. V.; Alam, I.; Saxena, A. K. Computer-aided discovery of anti-inflammatory thiazolidinones with dual cyclooxygenase/lipoxygenase inhibition. J. Med. Chem. 2008, 51, 1601-1609.

(68) Yan, S.; Appleby, T.; Larson, G.; Wu, J. Z.; Hamatake, R. K.; Hong, Z.; Yao, N. Thiazolone-acylsulfonamides as novel HCV NS5B polymerase allosteric inhibitors: convergence of structurebased drug design and X-ray crystallographic study. Bioorg. Med. Chem. Lett. 2007, 17, 1991-1995.

(69) Yan, S.; Larson, G.; Wu, J. Z.; Appleby, T.; Ding, Y.; Hamatake, R.; Hong, Z.; Yao, N. Novel thiazolones as HCV NS5B polymerase allosteric inhibitors: further designs, SAR and X-ray complex structure. Bioorg. Med. Chem. Lett. 2007, 17, 63-67.

(70) Ding, Y.; Smith, K. L.; Varaprasad, C. V. N. S.; Chang, E.; Alexander, J.; Yao, N. Synthesis of thiazolone-based sulfonamides as inhibitors of HCV NS5B polymerase. Bioorg. Med. Chem. Lett. 2007, 17, 841-845.

(71) Yan, S.; Appleby, T.; Larson, G.; Wu, J. Z.; Hamatake, R.; Hong, Z.; Yao, N. Structure-based design of a novel thiazolone scaffold as HCV NS5B polymerase allosteric inhibitors. Bioorg. Med. Chem. Lett. 2006, 16, 5888-5891.

(72) Shi, L.; Yu, H. P.; Zhou, Y. Y.; Du, J. Q.; Shen, Q.; Li, J. Y.; Li, J. Discovery of a novel competitive inhibitor of PTP1B by high-throughput screening. Acta Pharmacol. Sin. 2008, 29, 278284

(73) Johnston, P. A.; Foster, C. A.; Shun, T. Y.; Skoko, J. J.; Shinde, S.; Wipf, P.; Lazo, J. S. Development and implementation of a 384-well homogeneous fluorescence intensity high-throuphput screening assay to identify mitogen-activated protein kinase phosphatase-1 dual-specificity protein phosphatase inhibitors. Assay Drug Dev. Technol. 2007, 5, 319-333.

(74) Ciustea, M.; Silverman, J. E. Y.; Shudofsky, A. M. D.; Ricciardi, R. P. Identification of non-nucleoside synthesis inhibitors of vaccinia virus by high-throughput screening. J. Med. Chem. 2008, 51, 6563-6570.

(75) Desai, P. V.; Patny, A.; Sabnis, Y.; Tekwani, B.; Gut, J.; Rosenthal, P.; Srivastava, A.; Avery, M. Identification of novel parastic cysteine protease inhibitors using virtual screening. 1. The Chembridge database. J. Med. Chem. 2004, 47, 6609-6615.

(76) Vicini, P.; Geronikaki, A.; Incerti, M.; Zani, F.; Dearden, J.; Hewitt, M. 2-Heteroarylimino-5-benzylidene-4-thiazolidinones [sic] analogues of 2-thiazolylimino-5-benzylidene-4-thiazolidinones with antimicrobial activity: synthesis and structure-activity relationship. Bioorg. Med. Chem. 2008, 16, 3714-3724.
(77) Zhou, H.; Wu, S.; Zhai, S.; Liu, A.; Sun, Y.; Li, R.; Zhang, Y.; Ekins, S.; Swaan, P. W.; Fang, B.; Yan, B. Design, synthesis and cytoselective toxicity, structure-activity relationships, and pharmacophore of thiazolidinone derivatives targeting drugresistant lung cancer cells. J. Med. Chem. 2008, 51, 1242-1251.

(78) Galam, L.; Hadden, M. K.; Ma, Z.; Ye, Q.-Z.; Yun, B.-G.; Blagg, B. S. J.; Matts, R. L. High-throughput assay for the identification of Hsp90 inhibitors based on Hsp90-dependent refolding of firefly luciferase. Bioorg. Med. Chem. 2007, 15, 1939-1946.

(79) Carosati, E.; Budriesi, R.; Ioan, P.; Ugenti, M. P.; Frosini, M.; Fusi, F.; Corda, G.; Cosimelli, B.; Spinelli, D.; Chiarini, A.; Cruciani, G. Discovery of novel and cardioselective diltiazemlike calcium channel blockers via virtual screening. J. Med. Chem. 2008, 1, 5552-5565.

(80) Foloppe, N.; Chen, I.-J.; Davis, B.; Hold, A.; Morely, D.; Howes, R. A structure-based strategy to identify new molecular scaffolds targeting the bacterial ribosomal A-site. Bioorg. Med. Chem. 2004, 12, 935-947.

(81) Lu, Y.; Nikolovska-Coleska, Z.; Fang, X.; Gao, W.; Shangary, S.; Qiu, S.; Qin, D.; Wang, S. Discovery of a nanomolar inhibitor of the human murine double minute 2 (MDM2)-p53 interaction through an integrated, virtual database screening strategy. J. Med. Chem. 2006, 49, 3759-3762.

(82) Nikolovska-Coleska, Z.; Qiu, S.; Long, J.; Yang, C.-Y.; Larsen, M.; Tomita, Y.; Gee, P.; Yi, H.; Krajewski, K.; Stuckey, J.; Roller, P. P.; Wang, S. Discovery and characterization of new smallmolecule inhibitors of Mcl-1 by high-throughput screening. Proc. Am. Assoc. Cancer Res. 2008, 49, 987 (Abstract 4148).

(83) Ma, Y.; Kurtyka, C. A.; Boyapalle, S.; Sung, S.-S.; Lawrence, H.; Guida, W.; Cress, W. D. A small-molecule E2F inhibitor blocks growth in a melanoma culture model. Cancer Res. 2008, 68, 62926299.

(84) Herzig, Y.; Lerman, L.; Goldenberg, W.; Lerner, D.; Gottlieb, H. E.; Nudelman, A. Hydroxy-1-aminoindans and derivatives: preparation, stability and reactivity. J. Org. Chem. 2006, 71, 41304140 .

(85) Weinert, E. E.; Dondi, R.; Colloredo-Melz, S.; Frankenfield, K. N.; Mitchell, C. H.; Freccero, M.; Rokita, S. E. Substituents on quinone methides strongly modulate formation and stability of their nucleophilic adducts. J. Am. Chem. Soc. 2006, 128, 1194011947.

(86) Caulfield, M. J.; McAllister, D. J.; Russo, T.; Solomon, D. H. Complexes of benzene-1,2-diol Mannich bases. II Novel aluminium(III) complexes. Aust. J. Chem. 2001, 54, 383-389.

(87) Occipinti, G.; Bjorsvik, H.-R.; Tornroos, K. W.; Jensen, V. R. Ruthenium alkylidene complexes of chelating amine ligands. Organometallics 2007, 26, 5803-5814.

(88) Xie, Y.; Liu, Q.; Jiang, H.; Ni, J. Novel complexes of ligands containing phenol and alcohol groups: from polynuclear cluster, $1 \mathrm{D}$ coordination polymer to 2D supramolecular assemblies. Eur. J. Inorg. Chem. 2003, 4010-4016.

(89) Ghailane, R.; Marakchi, K.; Komiha, N.; Kabbaj, O. K.; Chraibi, M.; Habbadi, N.; Dartiguenave, M. A theoretical investigation of the conformational aspects of aminophenols and of their complexation with $\mathrm{BF}_{2}^{+}$and $\mathrm{ZnCl}_{2}$. J. Mol. Struct. (THEOCHEM) 2000, 531, 223-239.

(90) Koh, L. L · Ranford, J O ; Robinson, W. T; Svensson, J. O ; Tan, A. L. C. T.; Wu, D. Model for the reduced Schiff base intermediate between amino acids and pyridoxal: copper(II) complexes of $N$-(2-hydroxybenzyl)amino acids with nonpolar side chains and crystal structures of $[\mathrm{Cu}(N-(2$-hydroxybenzyl $)-\mathrm{D}, \mathrm{L}-$ alanine $)($ phen $)] \cdot \mathrm{H}_{2} \mathrm{O}$ and $[\mathrm{Cu}(N-(2$-hydroxybenzyl)-D, L-alanine)(imidazole)]. Inorg. Chem. 1996, 35, 6466-6472.

(91) Junker, L. M.; Clardy, J. High-throughput screens for smallmolecule inhibitors of Pseudomonas aeruginosa biofilm development. Antimicrob. Agents Chemother. 2007, 51, 3582-3590.

(92) McLean, L. R.; Zhang, Y.; Li, H.; Li, Z.; Lukasczyk, U.; Choi, Y.-M.; Han, Z.; Prisco, J.; Fordham, J.; Tsay, J. T.; Reiling, S.; Vaz, R. J.; Li, Y. Discovery of covalent inhibitors for MIF tautomerase via cocrystal structures with phantom hits from virtual screening. Bioorg. Med. Chem. Lett. 2009, 23, $6717-6720$

(93) Oyamada, Y.; Ito, H.; Fujimoto-Nakamura, M.; Tanitame, A.; Iwai, N.; Nagai, K.; Yamagishi, J.-I.; Wachi, M. A nucleate cell blue assay: a useful tool for identifying novel type II topoisomerase inhibitors. Antimicrob. Agents Chemother. 2006, 50, 348-350.

(94) Min, D.-H.; Tang, W.-J.; Mrksich, M. Chemical screening by mass spectrometry to indentify inhibitors of anthrax lethal factor. Nat. Biotechnol. 2004, 22, 717-723.

(95) Finn, J.; Stidham, M.; Hilgers, M.; Kedar, G. C. Identification of novel inhibitors of methionyl-tRNA synthetase (MetRS) by virtual screening. Bioorg. Med. Chem. Lett. 2008, 18, 3932-3937. 
(96) Schuster, D.; Nashev, L. G.; Kirchmair, J.; Laggner, C.; Wolber, G.; Langer, T.; Odermatt, A. Discovery of nonsteroidal 17betahydroxysteroid dehydrogenase 1 inhibitors by pharmacophorebased screening of virtual compound libraries. J. Med. Chem. 2008, 51, 4188-4199.

(97) Manetti, F.; Magnani, M.; Castagnolo, D.; Passalacqua, L.; Botta, M.; Corelli, F.; Saddi, M.; Deidda, D.; De Logu, A. Ligand-based virtual screening, parallel solution-phase and microwave-assisted synthesis as tools to identify and synthesize new inhibitors of Mycobacterium tuberculosis. ChemMedChem 2006, 1, 973-989.

(98) Kauppi, A. M.; Nordelth, R.; Uveil, H.; Wolf-Watz, H.; Elofsson, M. Targeting bacterial virulence: inhibitors of type III secretion in Yersinia. Chem. Biol. 2003, 10, 241-249.

(99) Park, H.; Hwang, K. Y.; Oh, K. H.; Kim, Y. H.; Lee, J. Y.; Kim, $\mathrm{K}$. Discovery of novel $\alpha$-glucosidase inhibitors based on virtual screening with the homology-modeled protein structure. Bioorg. Med. Chem. 2008, 16, 284-292.

(100) Chenna, B. C.; Shinkre, B. A.; King, J. R.; Lucius, A. L.; Narayana, S. V. L.; Velu, S. E. Identification of novel inhibitors of bacterial surface enzyme Staphylococcus aureus Sortase A. Bioorg. Med. Chem. Lett. 2008, 18, 380-385.

(101) Auld, D. S.; Southall, N. T.; Jadhav, A.; Johnson, R. L.; Diller, D. J.; Simeonov, A.; Austin, C. P.; Inglese, J. Characterization of chemical libraries for luciferase inhibitory activity. J. Med. Chem. 2008, 51, 2372-2386.

(102) Dilovic, I.; Rubcic, M.; Vrdoljak, V.; Pavelic, S. K.; Kralj, M.; Piantanida, I.; Cindric, M. Novel thiosemicarbazone derivatives as potential antitumor agents: synthesis, physicochemical and structural properties, DNA interactions and antiproliferative activity. Bioorg. Med. Chem. 2008, 16, 5189-5198.

(103) Ledesma, G. N.; Sierra, M. G.; Escandar, G. M. Spectroscopic and theoretical study or aromatic $\alpha$-hydroxy hydrazones and their copper (II) complexes in dioxane-water mixtures. Polyhedron 1998, 17, 1517-1523

(104) Ainscough, E. W.; Brodie, A. M.; Denny, W. A.; Finlay, G. J.; Gothe, S. A.; Ranford, J. D. Cytotoxicity of salicylaldehyde benzoylhydrazone analogs and their transition metal complexes: quantitative structure-activity relationships. J. Inorg. Biochem. 1999, 77, 125-133.

(105) Ifa, D. R.; Rodrigues, C. R.; de Alencastro, R. B.; Fraga, C. A. M.; Barriero, E. J. A possible molecular mechanism for the inhibition of cysteine proteases by salicylaldehyde $N$-acylhydrazones and related compounds. J. Mol. Struct. (THEOCHEM) 2000, 505, 11-17.

(106) Cilenti, L.; Lee, Y.; Hess, S.; Srinivasula, S.; Park, K. M.; Junqueira, D.; Davis, H.; Bonventre, J. V.; Alnemri, E. S.; Zervos, A. S. Characterization of a novel and specific inhibitor for the pro-apoptotic protease Omi/HtrA2. J. Biol. Chem. 2003, 278, 11489-11494.

(107) Yang, H.; Shelat, A. A.; Guy, R. K.; Gopinath, V. S.; Ma, T.; Du, K.; Lukacs, G. L.; Taddei, A.; Folli, C.; Pedemonte, N.; Galietta, L. J. V.; Verkman, A. S. Nanomolar affinity small molecule correctors of defective $\triangle F 508-C F T R$ chloride channel gating. J. Biol. Chem. 2003, 278, 35079-35085.

(108) Chen, F.; Hancock, C. N.; Macias, A. T.; Joh, J.; Still, K.; Zhong, S.; MacKerell, A. D., Jr; Shapiro, P. Characterization of ATPindependent ERK inhibitors identified through in silico analysis of the active ERK2 structure. Bioorg. Med. Chem. Lett. 2006, 16, 6281-6287.

(109) Hartzoulakis, B.; Rossiter, S.; Gill, H.; O'Hara, B. O.; Steinke, E.; Gane, P. A.; Hurtado-Guerrero, R.; Leiper, J. M.; Vallance, P.; Murray Rust, J; Selwood, D. L. Discovery of inhibitors of the pentein superfamily protein dimethylarginine dimethylaminohydrolase (DDAH), by virtual screening and hit analysis. Bioorg. Med. Chem. Lett. 2007, 17, 3953-3956.

(110) Richardson, R. D.; Smith, J. W. Novel antagonists of the thioesterase domain of human fatty acid synthase. Mol. Cancer Ther. 2007, 6, 2120-2126.

(111) Rayter, S.; Elliott, R.; Travers, J.; Rowlands, M. G.; Richardson, T. B.; Boxall, K.; Jones, K.; Linardopoulos, S.; Workman, P.; Aherne, W.; Lord, C. J.; Ashworth, A. A chemical inhibitor of PPM1D that selectively kills cells overexpressing PPM1D. Oncogene 2008, 27, 1036-1044.

(112) Park, H.; Hwang, K. Y.; Kim, Y. H.; Oh, K. H.; Lee, J. Y.; Kim, $\mathrm{K}$. Discovery and biological evaluation of novel $\alpha$-glucosidase inhibitors with in vivo antidiabetic effect. Bioorg. Med. Chem. Lett. 2008, 18, 3711-3715.

(113) Harriman, G. C.; Brewer, M.; Bennett, R.; Kuhn, C.; Bazin, M.; Larosa, G.; Skerker, P.; Cochran, N.; Gallant, D.; Baxter, D.; Picarella, D.; Jaffee, B.; Luly, J. R.; Briskin, M. J. Selective cell adhesion inhibitors: barbituric acid based $\alpha 4 \beta 7$-MAdCAM inhibitors. Bioorg. Med. Chem. Lett. 2008, 18, 2509-2512.
(114) Andre, E.; Bastide, L.; Villian-Guillot, P.; Latouche, J.; Rouby, J.; Leonetti, J. P. A multiwell assay to isolate compounds inhibiting the assembly of the prokaryotic RNA polymerase. Assay Drug Dev. Technol. 2004, 2, 629-636.

(115) Tanaka, K.; Chen, X.; Kimura, T.; Yoneda, F. 5-Arylidene 1,3dimethylbarbituric acid derivatives, mild organic oxidants for allylic and benzylic alcohols. Chem. Pharm. Bull. 1988, 36, 60-69.

(116) Meissner, J. W. G.; van der Laan, A. C.; Pandit, U. K. Reduction of 5-aylidenebarbiturate derivatives by thiols. Tetrahedron Lett. 1994, 35, 2757-2760.

(117) Tanaka, K.; Chen, X.; Yoneda, F. Oxidation of thiol with 5-arylidene-1,3-dimethylbarbituric acid: application to synthesis of unsymmetrical disulfide. Tetrahedron 1988, 44, 3241-3249.

(118) Shazib, P.; Harriman, A.; Gulliya, K. S. Protein damage by photoproducts of merocyanine 540. Free Radical Biol. Med. 1992, 12, 389-396.

(119) Yamazaki, K.; Kusunose, N.; Fujiita, K.; Sato, H.; Asano, S.; Dan, A.; Kanaoka, M. Identification of phosphodiesterase-1 and 5 dual inhibitors by a ligand-based virtual screening optimized for lead evolution. Bioorg. Med. Chem. Lett. 2006, 16, 1371-1379.

(120) Manetti, F.; Locatelli, G. A.; Maga, G.; Schenone, S.; Modugno, M.; Forli, S.; Corelli, F.; Botta, M. A combination of docking/ dynamics simulations and pharmacophore modelling to discover new dual c-Src/Abl kinase inhibitors. J. Med. Chem. 2006, 49 , 3278-3286.

(121) Yang, Y.; Kitagaki, J.; Dai, R.-M.; Tsai, Y. C.; Lorick, K. L.; Ludwig, R. L.; Pierre, S. A.; Jensen, J. P.; Davydov, I. V.; Oberoi, P.; Li, C.-C.; Kenten, J. H.; Beutler, J. A.; Vousden, K. H.; Weissman, A. M. Inhibitors of ubiquitin-activating enzyme (E1), new class of potential cancer therapeutics. Cancer Res. 2007, 67, 9472-9481.

(122) Mukherjee, P.; Desai, P.; Ross, L.; White, E. L.; Avery, M. A Structure-based virtual screening against SARS-3CL ${ }^{\text {pro }}$ to identify novel nonpeptidic hits. Bioorg. Med. Chem. 2008, 16, 4138-4149.

(123) Deng, G.; Li, W.; Shen, J.; Jiang, H.; Chen, K.; Liu, H. Pyrazolidine-3,5-dione derivatives as potent nonsteroidal agonists of farnesoid X receptor: virtual screening, synthesis and biological evaluation. Bioorg. Med. Chem. 2008, 18, 5497-5502.

(124) Tintori, C.; Manetti, F.; Velijkovic, N.; Perovic, V.; Vercammen, J.; Hayes, S.; Massa, S.; Witvrouw, M.; Debyser, Z.; Veljkovic, V.; Botta, M. Novel virtual screening protocol based on the combined use of molecular modelling and electron-ion interaction potential techniques to design HIV-1 integrase inhibitors. J. Chem. Inf. Model. 2007, 47, 1536-1544.

(125) Kao, R. Y. T.; Jenkins, J. L.; Olson, K. A.; Key, M. E.; Fett, J. W.; Shapiro, R. A small molecule inhibitor of the ribonucleolytic activity of human angiogenin that possesses antitumor activity. Proc. Natl. Acad. Sci. U.S.A. 2002, 99, 10066-10071.

(126) Jenkins, J. L.; Kao, R. Y. T.; Shapiro, R. Virtual screening to enrich hit lists from high throughput screening. A case study on small-molecule inhibitors of angiogenesis. Proteins: Struct., Funct., Genet. 2003, 50, 81-93

(127) Hoffman, B.; Franke, L.; Proschak, E.; Tanrikulu, Y.; Schneider, P.; Steinhilber, D.; Schneider, G. Scaffold-hopping cascade yields potent inhibitors of 5-lipoxygenase. ChemMedChem. 2008, 3, 1535 .

(128) Shimomura, O. The structure of the chromophore of Aequorea green fluorescent protein. FEBS Lett. 1979, 104, 220-222.

(129) Chen, D.; Misra, M.; Sower, L.; Peterson, J. W.; Kellogg, G. E.; Schein, C. H. Novel inhibitors of anthrax edema factor. Bioorg. Med. Chem. 2008, 16, 7225-7233.

(130) Vidal, D.; Blobel, J.; Perez, Y.; Thormann, M.; Pons, M. Structure-based discovery of new small molecule inhibitors of low molecular weight protein tyrosine phosphatase. Eur. J. Med. Chem. 2007, 42, 1102-1108.

(131) Fukunishi, Y.; Mikami, Y.; Takedomi, K.; Yamanouchi, M.; Shima, H.; Nakamura, H. Classification of chemical compounds by protein-compound docking for use in designing a focused library. J. Med. Chem. 2006, 49, 523-533.

(132) Eswaran, J.; von Kries, J. P.; Marsden, B.; Longman, E.; Debreczini, J. E.; Ugochukwu, E.; Turnbull, A.; Lee, W. H.; Knapp, S.; Barr, A. J. Crystal structures and inhibitor identification for PTPN5, PTPRR and PTPN7: a family of human MAPK-specific protein tyrosine phosphatases. Biochem. J. 2006, 395, 483-491.

(133) Brisson, M.; Nguyen, T.; Vogt, A.; Yalowich, J.; Giorgianni, A.; Tobi, D.; Bahar, I.; Stephenson, C. R. J.; Wipf, P.; Laso, J. S. Discovery and Characterization of Novel Small Inhibitors of Human Cdc25B Dual Specificity Phosphatase. Mol. Pharmacol. 2004, 66, 824-833.

(134) Sharlow, E. R.; Leimgruber, S.; Shun, T. Y.; Lazo, J. S. Development and implementation of a minitaturized high-throughput 
time-resolved fluorescence energy transfer assay to identify small molecule inhibitors of polo-like kinase 1. Assay Drug Dev. Technol. 2007, 5, 723-35.

(135) Jiang, S.; Lu, H.; Liu, S.; Zhao, Q.; He, Y.; Debnath, A. K. N-Substituted pyrrole derivatives as novel human immunodeficiency virus type 1 entry inhibitors that interfere with the gp41 sixhelix bundle formation and block virus fusion. Antimicrob. Agents Chemother. 2004, 48, 4349-4359.

(136) Manger, M.; Scheck, M.; Prinz, H.; von Kries, J. P.; Langer, T.; Saxena, K.; Schwalbe, H.; Fuerstner, A.; Rademann, J.; Waldmann, $\mathrm{H}$. Discovery of Mycobacterium tuberculosis protein tyrosine phosphatase A (MptpA) inhibitors based on natural products and a fragment-based approach. ChemBiochem 2005, 6, 1749-1753.

(137) Schuerer, S. C.; Brown, S. J.; Gonzalez-Cabrera, P. J.; Schaeffer, M.-T.; Chapman, J.; Jo, E.; Chase, P.; Spicer, T.; Hodder, P.; Rosen, H. Ligand-binding pocket shape differences between sphingosine 1-phosphate (S1P) receptors S1P1 and S1P3 determine efficiency of chemical probe identification by ultrahighthroughput screening. ACS Chem. Biol. 2008, 3, 486-498.

(138) Noberini, R.; Koolpe, M.; Peddibhotla, S.; Dahl, R.; Su, Y.; Cosford, N. D. P.; Roth, G. P.; Pasquale, E. B. Small molecules can selectively inhibit ephrin binding to the EphA4 and EphA2 receptors. J. Biol. Chem. 2008, 283, 29461-29472.

(139) Renner, S.; Hechenberger, M.; Noeske, T.; Boecker, A.; Jatzke, C.; Schmuker, M.; Parsons, C. G.; Weil, T.; Schneider, G. Searching for drug scaffolds with $3 \mathrm{D}$ pharmacophore and neural network ensembles. Angew. Chem., Int. Ed. 2007, 46, 5336-5339.

(140) Liu, K.; Lu, H.; Hou, L.; Qi, Z; Teixeira, C.; Barbault, F.; Fan, B.-T.; Liu, S.; Jiang, S.; Xie, L. Design, synthesis and biological evaluation of $N$-carboxyphenylpyrrole derivatives as potent HIV fusion inhibitors targeting gp41. J. Med. Chem. 2008, 51, 7843-7854.

(141) Herschhorn, A.; Hizi, A. Virtual screening, identification, and biochemical characterization of novel inhibitors of the reverse transcriptase of human immunodeficiency virus type-1. J. Med. Chem. 2008, 51, 5702-5713.

(142) Podust, L. M.; von Kries, J. P.; Eddine, A. N.; Kim, Y.; Yermalitskaya, L. V.; Kuehne, R.; Ouellet, H.; Warrier, T.; Altekoester, M.; Lee, J.-S.; Rademann, J.; Oschkinat, H.; Kaufmann, S. H. E.; Waterman, M. R. Small-molecule scaffolds for CYP51 inhibitors identified by highthroughput screening and defined by X-ray crystallography. Antimicrob. Agents Chemother. 2007, 51, 3915-3923.

(143) Kauppi, A. M.; Andersson, C. D.; Norberg, H. A.; Sundin, C.; Linusson, A.; Elofsson, M. Inhibitors of type III secretion in Yersinia: design, synthesis and multivariate QSAR of 2-arylsulfonylamino-benzanilides. Bioorg. Med. Chem. 2007, 15, 69947011.

(144) White, L. K.; Yoon, J.-J.; Lee, J. K.; Sun, A.; Du, Y.; Fu, H.; Snyder, J. P.; Plemper, R. K. Nonnucleoside inhibitor of measles virus RNA-dependent RNA polymerase complex activity. Antimicrob. Agents Chemother. 2007, 51, 2293-2303.

(145) Allison, B. D.; Phuong, V. K.; McAtee, L. C.; Rosen, M.; Morton, M.; Prendergast, C.; Barrett, T.; Lagaud, G.; Freedman, J.; Li, L.; Wu, X.; Hariharan, V.; Pippel, M.; Woods, C.; Rizzolio, M. C.; Hack, M.; Hoey, K.; Deng, X.; King, C.; Shankley, N. P.; Rabinowitz, M. H. Identification and optimization of anthranilic sulfonamides as novel, selective cholecystokinin-2 receptor antagonists. J. Med. Chem. 2006, 49, 6371-6390.

(146) Kumar, A.; Chaturvedi, V.; Bhatnagar, S.; Sinha, S.; Siddiqi, M. I. Knowledge based identification of potent antitubercular compounds using structure based virtual screening and structure interaction fingerprints. J. Chem. Inf. Model. 2009, 49, 35-42.

(147) Schuler, A. D.; Si, J.; Mueller, L.; Simon, J. A.; Collins, S. J. $\mathrm{KN}-62$ analogues as potent differentiating agents of HL-60 cells. Leuk. Res. 2007, 31, 683-689.

(148) Uchiyama, S.; Santa, T.; Imai, K. Development of hydrophilic fluorogenic derivatization reagents for thiols: 4- $(N$-acetylaminosulfonyl)-7-fluoro-2,1,3-benzoxadiazole and 4-( $N$-trichloroacetylaminosulfonyl)-7-fluoro-2,1,3-benzoxadiazole. J. Chromatogr. A 2002, 982, 111-118

(149) Uchiyama, S.; Santa, T.; Okiyama, N.; Fukushima, T.; Imai, K. Fluorogenic and fluorescent reagents with a benzofuran skeleton. Biomed. Chromatogr. 2001, 15, 295-318

(150) Takabatake, T.; Miyazawa, T.; Hasegawa, M.; Foote, C. S. Reaction of 4,7-dimethylbenzofuran with singlet oxygen. Tetrahedron Lett. 2001, 42, 987-989.

(151) Morgan, R. E.; Ahn, S.; Nzimiro, S.; Fotie, J.; Phelps, M. A.; Cotrill, J.; Yakovich, A. J.; Sackett, D. L.; Dalton, J. T.; Werbovetz, K. A. Inhibitors of tubulin assembly identified through screening a compound library. Chem. Biol. Drug Des. 2008, 72, 513-524.

(152) Wendeler, M.; Lee, H.-F.; Bermingham, A.; Miller, J. T.; Chertov, O.; Bona, M. K.; Baichoo, N. S.; Ehteshami, M.; Beutler, J.;
O'Keefe, B. R.; Goette, M.; Kvaratskahelia, M.; Le Grice, S. Vinylogous ureas as a novel class of inhibitors of reverse transcriptase-associated ribonuclease $\mathrm{H}$ activity. ACS Chem. Biol. 2008, 3, 635-644.

(153) Louise-May, S.; Yang, W ; Nie, X ; Liu, D ; Deshpande, M. S. Phadke, A. S.; Huang, M.; Agarwal, A. Discovery of novel dialkyl-substituted thiophene inhibitors of HCV by in silico screening of the NS5B RdRp. Bioorg. Med. Chem. Lett. 2007, 17, 3905-3909.

(154) Patch, R. J.; Baumann, C. A.; Liu, J.; Gibbs, A. C.; Ott, H.; Lattanze, J.; Player, M. R. Identification of 2-acylaminothiophene-3-carboxamides as potent inhibitors of FLT3. Bioorg. Med. Chem. Lett. 2006, 16, 3282-3286.

(155) Soelaiman, S.; Wei, B. Q.; Bergson, P.; Lee, Y.-S.; Shen, Y.; Mrksich, M.; Shoichet, B. K.; Tang, W.-J. Structure-based inhibitor discovery against adenylyl cyclase toxins from pathogenic bacteria that cause anthrax and whooping cough. J. Biol. Chem. 2003, 278, 25990-25997.

(156) Broom, W. J.; Auwarter, K. E.; Ni, J.; Russel, D. E.; Yeh, L.-A.; Maxwell, M. M.; Glicksman, M.; Kazantsev, A. G.; Brown, R. H., Jr. Two approaches to drug discovery in SOD1-mediated ALS. J. Biomol. Screening 2006, 11, 729-735.

(157) Huth, J. R.; Mendoza, R.; Olejniczak, E. T.; Johnson, R. W.; Cothron, D. A.; Liu, Y.; Lerner, C. G.; Chen, J.; Hajduk, P. ALARM NMR: A rapid and robust experimental method to detect reactive false positives in biochemical screens. J. Am. Chem. Soc. 2005, 127, 217-224.

(158) Sleno, L.; Staack, R. F.; Varesio, E.; Hopfgartner, G. Investigating the in vitro metabolism of fipexide: characterization of reactive metabolites using liquid chromatography/mass spectrometry. Rapid Commun. Mass Spectrom. 2007, 21, 2301-2311.

(159) Dietrich, L. E. P.; Teal, T. K.; Price-Whelan, A.; Newman, D.K. Redox-Active Antibiotics Control Gene Expression and Community Behavior in Divergent Bacteria. Science 2008, 321, 12031206.

(160) Li, W. W.; Heinze, J.; Haehnel, W. Site-specific binding of quinones to proteins through thiol addition and addition-elimination reactions. J. Am. Chem. Soc. 2005, 127, 6140-6141.

(161) Liu, X.; Sok, D. Identification of alkylation-sensitive target chaperone proteins and their reactivity with natural products containing Michael acceptor. Arch. Pharm. Res. 2003, 26, 10471054.

(162) Dolphin, G. T.; Ouberai, M.; Dumy, P.; Garcia, J. Designed amyloid beta peptide fibril-a tool for high throughput screening of fibril inhibitors. ChemMedChem 2007, 2, 1613-1623.

(163) Honson, N. S.; Johnson, R. L.; Huang, W.; Inglese, J.; Austin, C. P.; Kuret, J. Differentiating Alzheimer disease-associated aggregates with small molecules. Neurobiol. Dis. 2007, 28, 251260.

(164) Necula, M.; Kayed, R.; Milton, S.; Glabe, C. G. Small molecule inhibitors of aggregation indicate that amyloid beta oligomerization and fibrillization pathways are independent and distinct. J. Biol. Chem. 2007, 282, 10311-1.

(165) Cheng, L. S.; Amaro, R. E.; Xu, D.; Li, W. W.; Arzberger, P. W ; McCammon, J. A. Ensemble-based virtual screening reveals potential novel antiviral compounds for avian influenza neuraminidase. J. Med. Chem. 2008, 51,3878-3894.

(166) Enyedy, I. J.; Ling, Y.; Nacro, K.; Tomita, Y.; Wu, X.; Cao, Y.; Guo, R.; Li, B.; Zhu, X.; Huang, Y.; Long, Y.-Q.; Roller, P. P.; Yang, D.; Wang, S. Discovery of small-molecule inhibitors of Bcl-2 through structure-based computer screening. J. Med. Chem. 2001, 44, 4313-4424.

(167) Boulegue, C.; Loeweneck, M.; Renner, C.; Moroder, L. Redox potential of azobenzene as an amino acid residue in peptides. ChemBioChem 2007, 8, 591-594

(168) Burns, S.; Travers, J.; Collins, I.; Rowlands, M. G.; Newbatt, Y.; Thompson, N.; Garrett, M. D.; Workman, P.; Aherne, W. Identification of small-molecule inhibitors of protein kinase B (PKB/AKT) in an AlphaScreen high-throughput screen. J. Biomol. Screening 2006, 11, 822-827.

(169) Oballa, R. M.; Truchon, J.-F.; Bayly, C. I.; Chauret, N.; Day, S.; Crane, S.; Berthelette, C. A generally applicable method for assessing the electrophilicity and reactivity of diverse nitrilecontaining compounds. Bioorg. Med. Chem. Lett. 2007, 17, 9981002.

(170) Call, M. J.; Xing, X.; Cuny, G. D.; Seth, N. P.; Altmann, D. M.; Fugger, L.; Krogsgaard, M.; Stein, R. L.; Wucherpfennig, K. W. In vivo enhancement of peptide display by MHC class II molecules with small molecule catalysts of peptide exchange. J. Immunol. 2009, 182, 6342-6352.

(171) Johnston, P. A.; Foster, C. A.; Shun, T. Y.; Skoko, J. J.; Shinde, S.; Wipf, P.; Laso, J. S. Development and implementation of a 
384-well homogenous fluorescence intensity high-throughput screening assay to identify mitogen-activated protein kinase phosphatase-1 dual-specificity protein phosphatase inhibitors. Assay Drug Dev. Technol. 2007, 5, 319-332.

(172) Neres, J.; Brewer, M. L.; Ratier, L.; Botti, H.; Buschiazzo, A. Edwards, P. N.; Mortenson, P. N.; Charlton, M. H.; Alzari, P. M.; Frasch, A. C.; Bryce, R. A.; Douglas, K. T. Discovery of novel inhibitors of Trypanosoma cruzi trans-sialidase from in silico screening. Bioorg. Med. Chem. Lett. 2009, 19, 589-596.

(173) Sanghani, P. Materials and methods for inhibiting mammalian $S$-nitrosoglutathione reductase. Patent WO 2009/076665 A1 (PCT/IS2008/086738), 2008.

(174) Wolan et al. (ref 218) have recently described 3-carboxamidocoumarins as useful proenzyme activators. From a medicinal chemistry point of view and for the purposes of library expansion, we had recently flagged such compounds as potentially problematically reactive. However, analysis reveals that the 72 examples in our library have an enrichment of only $9.6 \%$ and so they do not appear to be problematic whatsoever. This is in stark contrast to the case of indole3-acetamide-2-carboxylic acids, for example, which on the surface appear benign but which we find to be problematic screening compounds. This evidence-based analysis is a useful and less subjective approach to constructing functional group filters and may allow for inclusion of useful chemical diversity that may currently frequently be filtered out based on unfounded prejudice. There are many functional groups such as epoxides for which we have no evidence whether they are problematic assay interference compounds or not because they were removed prior to library development. It is certainly the case that in a "one-off" assay (ref 213), commonly removed screening compounds such as cyanamides, cyanohydrins, perhaloketones, and epoxides were not over-represented in the set of primary hits, but the ultimate arbiter may be what structures a medicinal chemist is prepared to work with.

(175) Young, R. H.; Brewer, D.; Kayser, R.; Martin, R.; Feriozi, D.; Keller, R. A. Mechanism of quenching by amines. New method for investigation of interactions with triplet states. Can. J. Chem. 1974, 52, 2889-2893.

(176) Zitha-Bovens, E.; Maas, P.; Wife, D.; Tijhuis, J.; Hu, Q.-N.; Kleinoeder, T.; Gasteiger, J. COMDECOM: Predicting the lifetime of screening compounds in DMSO solution. J. Biomol. Screening 2009, 14, 557-565.

(177) Kaumanns, O.; Mayr, H. Electrophilicity parameters of 5-benzylidene-2,2-dimethyl[1,3]dioxane-4,6-diones (benzylidene Meldrum's acids). J. Org. Chem. 2008, 73, 2738-2745.

(178) Guo, J.; Parise, R. A.; Joseph, E.; Egorin, M. J.; Lazo, J. S.; Prochownik, E. V.; Eiseman, J. L. Efficacy, pharmacokinetics, tissue distribution, and metabolism of the Myc-Max disruptor, 10058-F4 [Z,E]-5-[4-ethylbenzylidine]-2-thioxothiazolidin-4-one, in mice. Cancer Chemother. Pharmacol. 2009, 63, 615-625.

(179) Degterev, A.; Lugovsky, A.; Cardone, M.; Mulley, B.; Wagner, G.; Mitchison, T.; Yuan, J. Identification of small-molecule inhibitors of the interaction between the BH3 domain and Bcl$\mathrm{x}_{\mathrm{L}}$. Nat. Cell Biol. 2001, 3, 173-182.

(180) van Delft, M. F.; Wei, A. H.; Mason, K. D.; Vandenberg, C. J.; Chen, L.; Czabotar, P. E.; Willis, S. N.; Scott, C. L.; Day, C. L.; Cory, S.; Adams, J. M.; Roberts, A. W.; Huang, D. C. S. The BH3 mimetic ABT-737-targets selective Bcl-2 proteins and efficiently induces apoptosis via Bak/Bax if $\mathrm{Mcl}-1$ is neutralized. Cancer Cell 2006, 10, 389-399.

(181) Pearce, B.; Sofia, M. J.; Good, A. C.; Drexler, D. M.; Stock, D. A. An empirical process for the design of high-throughput screening deck filters. J. Chem. Inf. Model. 2006, 46, 1060-1068.

(182) Lor, L. L.; Schneck, J.; McNulty, D. E.; Diaz, E.; Brandt, M.; Thrall, S. H.; Schwartz, B. A simple assay for detection of small-molecule redox activity. J. Biomol. Screening 2007, 12, 881-890.

(183) Johnston, P. A.; Soares, K. M.; Shinde, S. N.; Foster, C. A.; Shun, T. Y.; Takyi, H. K.; Wipf, P.; Lazo, J. S. Development of a 384well colorimetric assay to quantify hydrogen peroxide generated by the redox cycling of compounds in the presence of reducing agents. Ass. Drug Dev. Technol. 2008, 6, 505-518.

(184) Du, J.-Q.; Wu, J.; Zhang, H.-J.; Zhang, Y.-H.; Qiu, B.-Y.; Wu, F.; Chen, Y.-H.; Li, J.-Y.; Nan, F.-J.; Ding, J.-P.; Li, J. Isoquinoline1,3,4-trione derivatives inactivate caspase-3 by generation of reactive oxygen species. J. Biol. Chem. 2008, 283, 30205-30215.

(185) It is not clear in refs 92 and 184 whether protein-reactive and timedependent activity is seen as a development limitation, but we would suggest that such behaviour in a screening hit is. Some good examples of unusual Hill coefficients are shown in ref 213.

(186) Guedat, P.; Colland, F. Patented small molecule inhibitors in the ubiquitin proteasome system. BMC Biochem. 2007, 8 (Suppl. I), S14.
(187) Seidler, J.; McGovern, S. L.; Doman, T. N.; Shoichet, B. K. Identification and prediction of promiscuous aggregating inhibitors among known drugs. J. Med. Chem. 2003, 46, 4477-4486.

(188) Camps, M.; Rueckle, T.; Ji, H.; Ardissone, V.; Rintelen, F.; Shaw, J.; Ferrandi, C.; Chabert, C.; Gillieron, C.; Francon, B.; Martin, T.; Gretener, D.; Perrin, D.; Leroy, D.; Vitte, P.-A.; Hirsc, E.; Wymann, M. P.; Cirillo, R.; Schwarz, M.; Rommel, C. Blockade of PI3K $\gamma$ suppresses joint inflammation and damage in mouse models of rheumatoid arthritis. Nature Med. 2005, 11, 936-943.

(189) Pomel, V.; Klicic, J.; Covini, D.; Church, D. D.; Shaw, J. P.; Roulin, K.; Burgat-Charvillon, F.; Valognes, D.; Camps, M.; Chabert, C.; Gillieron, C.; Francon, G.; Perrin, D.; Leroy, D.; Gretener, D.; Nichols, A.; Vitter, P. A.; Carboni, S.; Romme, C.; Schwarz, M. K.; Rueckel, T. Furan-2ylmethylene thiazolidinediones as novel, potent, and selective inhibitors of phosphoinositide 3-kinase $\gamma$. J. Med. Chem. 2006, 49, 3857-3871.

(190) Kalgutkar, A. S.; Gardner, I.; Obach, R. S.; Shaffer, C. L.; Callegari, E.; Henne, K. R.; Mutlib, A. E.; Dalvie, D. K.; Lee, J. S.; Nakai, Y.; O’Donnell, J. P.; Boer, J.; Harriman, S. P. A comprehensive listing of bioactivation pathways of organic functional groups. Curr. Drug. Metab. 2005, 6, 161-225.

(191) Roche, O.; Schneider, P.; Zuegge, J.; Guba, W.; Kansy, M.; Alanine, A.; Bleicher, K.; Danel, F, F.; Gutknecht, E.-M.; Roger-Evans, M.; Neidhart, W.; Stalder, H.; Dillon, M.; Sjogren, E.; Fotouhi, N.; Gillespie, P.; Goodnow, R.; Harris, W.; Jones, P.; Taniguchi, M.; Tsujii, S.; von der Saal, W.; Zimmermann, G.; Schneider, G. Development of a virtual screening method for identification of "frequent hitters" in compound libraries. J. Med. Chem. 2002, 45, 137-142.

(192) Lu, X.; Li, C.; Fleisher, D. Cimetidine sulfoxidation in small intestinal microsomes. Drug Metab. Dispos. 1998, 26, 940-942.

(193) Levine, M.; Law, E. Y.; Bandiera, S. M.; Chang, T. K.; Bellward, G. D. In vivo cimetidine inhibits hepatic CYP2C6, CYP2C11 but not CYP1A1 in adult male rats. J. Pharmacol. Exp. Ther. 1998, 284, 493-499.

(194) Peppercorn, M. A. Sulfasalazine. Pharmacology, clinical use, toxicity and related new drug development. Ann. Intern. Med. 1984, 101, 377-386.

(195) Newell, D.; Gescher, A.; Harland, S.; Ross, D.; Rutty, C. $\mathrm{N}$-Methyl antitumour agents. A distinct class of anticancer drugs? Cancer Chemother. Pharmacol. 1987, 19, 91-102.

(196) Dunge, A.; Chakraborti, A. K.; Singh, S. Mechanistic explanation to the variable degradation behaviour of stavudine and zidovudine under hydrolytic, oxidative and photolytic conditions. J. Pharm. Biomed. Anal. 2004, 35, 965-970.

(197) Dahl, S. G. Active metabolites of neuroleptic drugs: possible contribution to therapeutic and toxic effects. Ther. Drug Monit. 1982, 4, 33-40.

(198) Miolo, G.; Levorato, L.; Gallocchio, F ; Caffieri, S ; Bastianon, C.; Zanoni, R.; Reddi, E. In vitro phototoxicity of phenothiazines: involvement of stable UVA photolysis products formed in aqueous medium. Chem. Res. Toxicol. 2006, 19, 156-163.

(199) Copeman, P. W. Phendione toxicity. Brit. Med. J. 1965, 2, 305.

(200) Kearney, A. S.; Patel, K.; Palepu, N. R. Preformulation studies to aid in the development of a ready-to-use injectable solution of the antitumour agent, topotecan. Int. J. Pharm. 1996, 127, 229-237.

(201) Xia, Q.; Chou, M. W.; Kadlubar, F. F.; Chan, P.-C.; Fu, P. P Human liver microsomal metabolism and DNA adduct formation of the tumorigenic pyrrolizidine alkaloid, riddelline. Chem. Res. Toxicol. 2003, 16, 66-73.

(202) Montanaro, S.; Lhiaubet-Vallet, V.; Iesce, M.; Previtera, L.; Miranda, M. A. A mechanistic study on the phototoxicity of atorvastatin: singlet oxygen generation by a phenanthrene-like photoproduct. Chem. Res. Toxicol. 2009, 22, 173-178.

(203) Guengerich, F. P.; Kim, D.-H.; Iwasaki, M. Role of human cytochrome P-450 IIE1 in the oxidation of many low molecular weight cancer suspects. Chem. Res. Toxicol. 1991, 4, 168-179.

(204) Buchan, P.; Keywood, C.; Wade, A.; Ward, C. Clinical pharmacokinetics of frovatriptan. Headache 2002, 42 (Suppl 2), S54-S62.

(205) Guttmann, P.; Ehrlich, P. Ueber die Wirkung des Methyleneblau bei Malaria. Berl. Klin. Wochenschr. 1891, 28, 953-956.

(206) Hugget, A. S.; Suffolk, S. F. The trypanocidal action of azo dyes. J. Pharmacol. Exp. Ther. 1936, 56, 188-193.

(207) Jacques, M. Intracellular parasite killing by electron carriers. I. Effect of electron carriers on intracellular Leishmania species I macrophages from different genetic backgrounds. Mol. Biochem. Parasitol. 1984, 13, 83-96.

(208) Howarth, J.; Lloyd, D. G. Redox systems as conduits for antimalarial compounds. J. Antimicrob. Chemother. 2001, 47, 122-124.

(209) Vennerstrom, J. L.; Makler, M. T.; Angerhofer, C. K.; Williams, J. A. Antimalarial dyes revisited: xanthenes, azines, and thiazines. Antimicrob. Agents Chemother. 1995, 39, 2671-2677. 
(210) Akilov, O. E.; Kosaka, S.; O'Riordan, K.; Hasan, T. Photodynamic therapy for cutaneous leishmaniasis: the effectiveness of topical phenothiaziniums in parasite eradication and Th1 immune response stimulation. Photochem. Photobiol. Sci. 2007, 6, 1067-1075.

(211) Target-based redox-active screening hits are not necessarily presented as poor development options (refs 184,219), and it is not clear that they always should be. However, we have recently identified certain pyrimido[5,4-e, $1,2,4]$ triazine- $5,7(1 \mathrm{H}, 6 \mathrm{H})$ diones as interesting target-based screening hits (data unpublished). A literature research reveals that these have been reported as potentially interesting trypanothione reductase inhibitors (ref 219) but also as nuisance redoxactive assay interference compounds (refs 182,183). We suggest the latter is more appropriate, and on this basis we abandoned this series. We note that this class is one of several that are emerging as problematic (probably redox-active) compounds that have evaded our filters because they did not significantly interfere in the six targets selected for study.

(212) It has been suggested that local hit rate (LHR) analysis can enhance HTS hit selection (ref 220) and reduce false positive follow-up. This may be true, but we would also caution that analogues of structurally well defined but protein-reactive classes such as rhodanines could pass LHR critieria as apparently true hits.

(213) Jadhav, A.; Ferreira, R. S.; Klumpp, C.; Mott, B. T.; Austin, C. P.; Inglese, J.; Thomas, C. J.; Maloney, D. J.; Shoichet, B. K.;
Simeonov, A. Quantitative analyses of aggregation, autofluorescence, and reactivity artefacts in a screen for inhibitors of a thiol protease. J. Med. Chem. 2009, DOI 10.1021/jm901070c. We note in this reference that rhodanines are recognized in filters, but with a medchem warning rather than a reactivity warning.

(214) Inglese, J.; Shamu, C. I.; Guy, R. K. Reporting screening data from high-throughput screening of small-molecule libraries. Nat. Chem. Biol. 2007, 3, 438-441.

(215) Garner, K. M.; Pletnev, A. A.; Eastman, A. Corrected structure of mirin, a small-molecule inhibitor of the Mre11-Rad50-Nbs1 complex. Nat. Chem. Biol. 2009, 5, 129.

(216) Toussant, M. Editorial. Chem. Eng. News 2009, 87, 3.

(217) Attardo, G.; Tripathy, S.; Gagnon, M. Arylmethylidene heterocycles as novel analgesics. Patent WO 2009/097695 A1 (PCT/ CA2009/000158), 2009

(218) Wolan, D. W.; Zorn, J. A.; Gray, D. C.; Wells, J. A. Smallmolecule activators of a proenzyme. Science 2009, 326, 853-858.

(219) Spinks, D.; Shanks, E. J.; Cleghorn, L. A. T.; McElroy, S.; Jones, D.; James, D.; Fairlamb, A. H.; Frearson, J. A.; Wyatt, P. G.; Gilbert, I. H. Investigation of trypanothione reductase as a drug target in Trypanosoma brucei. ChemMedChem 2009, 4, 20602069.

(220) Posner, B. A.; Xi, H.; Mills, J. E. J. Enhanced HTS hit selection via a local hit rate analysis. J. Chem. Inf. Model. 2009, 49, 2202-2210. 